\title{
La Edad del Bronce en el Noroeste de la Península Ibérica: un análisis a partir de las prácticas funerarias
}

\author{
The Bronze Age in the Northwestern of Iberian Peninsula: an analysis \\ from funerary practices
}

Ana M. S. Bettencourt (*)

\section{RESUMEN}

La autora ensaya una nueva interpretación de los mecanismos de negociación del poder y de promoción de la identidad social a partir del análisis de unas prácticas funerarias, cuya existencia ha quedado demostrada en todos los períodos de la Edad del Bronce en el Noroeste de la Península Ibérica, y de la integración de las mismas en los diferentes contextos cronológico-culturales en los que se desenvuelven. En esta extensa área distingue dos grandes tendencias en el tipo y la distribución de las arquitecturas funerarias que asocia a los diferentes modos de interacción y percepción del mundo de las comunidades de este período. Defiende que las necrópolis de sepulturas "opacas" (cistas sin tumuli, sepulturas planas y fosas), localizadas en áreas de importante potencial agrícola y en las inmediaciones de los poblados, fueron construidas por comunidades sedentarias, muy implicadas en actividades agrícolas, con un marcado sentido de la territorialización y un dominio y conocimiento profundo del territorio. En cambio las comunidades conectadas con paisajes montañosos, eventualmente mas subordinadas a las prácticas pastoriles y con modos de vida que implicarían mayor movilidad, serían las responsables de la construcción de estructuras funerarias más visibles, como los monumentos bajo tumuli de tradición megalítica, alejados de los poblados.

Defiende durante el Bronce Inicial una ocupación de nuevos territorios y la aparición tanto de una nueva forma de interacción de las comunidades con el medio como nuevos mecanismos de poder y de legitimación sobre el territorio que se materializan, parcialmente, en las prácticas funerarias. Atribuye un papel social a algunos cadáveres, aquellos que tienen ofrendas de cobre y de oro y que están presentes en lugares antiguos y nuevos.

(*) Prof. ${ }^{a}$ Auxiliar com Agregação do Departamento de História da Universidade do Minho, Campus de Gualtar, 4710 - 059 Braga, Portugal. Investigadora del "Centro de Investigação Transdisciplinar. Cultura, Espaço e Memória/Paisagens Fronteiras e Poderes - CITCEM/UM". Proyecto FCT-SFRH/BSAB/650/06.

Correo electrónico: anabett@uaum.uminho.pt

Recibido: 6-XI-2009; aceptado: 2-II-2010.
A partir del Bronce Medio asume que el cadáver pierde importancia en términos colectivos y que la muerte se vuelve más familiar, transfiriéndose los escenarios de negociación del poder y de la identidad social a otros contextos de acción más conectados con la esfera de los vivos. Pone como ejemplo los lugares de explotación de estaño y de fabricación, manipulación y deposición de artefactos en bronce, los escenarios donde se edifican y se colocan las estatuas-menhires emergentes, grabadas con armas y con nuevos símbolos, y el interior de los poblados.

Durante el Bronce Final esta dinámica se acentuaría, aumentando la transformación del cadáver con la consiguiente pérdida de importancia del cuerpo físico, sobre todo en los lugares o períodos en los que los indicios de incineración parecen más usuales. Destaca la mayor relevancia adquirida por los poblados como polos dinamizadores de poder y la aparición de localizaciones en alto, de verdaderos recintos excepcionales, a veces con murallas, en donde las acciones realizadas implicaron la manipulación de varios y diversificados artefactos metálicos, además de materias primas excepcionales y de gran cantidad de recipientes cerámicos singulares. Finaliza preconizando la necesidad de estudios de contingencia que permitan confirmar o refutar estas hipótesis.
ABSTRACT
From the analysis of the funerary practices and of their integration in the different chronological-cultural contexts where they develop, the author works out a new interpretation of the mechanism of negotiation of power and the promotion of social identity through the Bronze Age of the NW Iberian Peninsula. When studying an area so wide she distinguishes two great trends in the type and distribution of the funerary architectures throughout the Bronze Age that she associates with different ways of in- teraction with, and perception of, the world. Thus, she ar- gues that the necropolises of "cloudy" tombs (cists with- out tumuli, plain graves and pits), located in areas of great agricultural potential and close to the settlements, may have been constructed by sedentary communities, very involved in agricultural activities, with a great sense 
of territoriality and a great control over, and deep knowledge of, the territory. On the other hand the communities involved with mountain landscapes, eventually more related to cattle and with ways of life that would imply greater mobility, were responsible for the construction of more visible funerary structures, such as small tumuli of megalithic tradition, located away from the settlements.

In relation to the social role of the corpse, the author argues for the Early Bronze Age, that, the occupation of new territories, the emergence of a new form of community interaction with the environment and the emergence of new mechanisms of power and legitimacy of the territory were materialized in burial practices and in the social role of some corpses, in copper and gold grave goods. This social role was represented in old and new places.

From the Middle Bronze Age she assumes that the corpse loses importance in collective terms and that death becomes more familiar. The new settings of power negotiation and social identity are transferred to other contexts of action more connected with the sphere of the living. She relates as examples the places of exploitation of tin; the places of production, manipulation and deposition of artefacts in bronze; the arenas where communities built and placed the emerging statue-menhirs and in the interior of the settlements.

During the Late Bronze Age these dynamics would have been accented, with increase of the transformation of the corpse and the consequent loss of the importance of the physical body, over all in the places or periods where cremations seem to be more evident. She distinguishes the great importance assumed for settlements as centres of power and the development of places located on hilltops, true enclosures, sometimes surrounded by walls, and where there were actions that implied the manipulation of several, diversified metal goods, as well as other articles of exceptional raw materials and a great amount of exceptional ceramic containers. She finishes praising the necessity of contingency studies that allow us to confirm or to invalidate the assumptions made.

Palabras clave: Noroeste Peninsular; Edad del Bronce; Prácticas funerarias; Papel social del cadáver; Identidad grupal; Escenarios de poder.

Key words: Northwest of Iberian Peninsula; Bronze Age; Funerary practices; Social role of the corpses; Social identity; Places of power.

The dead can very well continue to be individuals, or even agents, after death (Fahlander y Oestigaard 2008)

\section{PRÁCTICAS FUNERARIAS EN LA EDAD DEL BRONCE DEL NOROESTE: HISTORIA}

Hasta finales de los años 1970, las publicaciones sobre contextos funerarios asignables a la
Edad del Bronce del Noroeste portugués eran escasas y frecuentemente relativas a hallazgos dispersos y fortuitos (Delgado 1887; Fortes 1906; Coelho 1925; Cardoso 1936; Ataíde y Teixeira 1940; Viana 1955; Alves 1975; etc.) salvo los efectuados por P. Kalb y M. Hock (1979) que dieron a conocer los primeros monumentos de la Edad del Bronce excavados científicamente, en la Beira Alta. Sin embargo, el mayor protagonismo corresponde al "Campo Arqueológico da Serra da Aboboreira", liderado por Vítor y Susana Oliveira Jorge que, a partir de 1978, detectarán, excavarán y publicarán nuevos contextos tumulares fechados entre el Neolítico y la Edad del Bronce (V. Jorge 1980, 1982, 1992; V. Jorge et al. 1988; S. Jorge 1980a, 1980b, 1983). Este proyecto por la calidad de los resultados y por las problemáticas que suscitó fue, en gran parte, inspirador de otros trabajos de investigación sobre el mundo funerario de la Prehistoria Reciente, a partir de finales de los años 1980. Tales trabajos incidirán en regiones como Trás-os-Montes, Minho, Beira Alta, Beira y Douro Litoral contribuyendo, si bien de modo desigual, a ampliar los conocimientos sobre el mundo tumular de la Edad del Bronce (Silva y Marques 1984, 1986; F.P. Silva 1992, 1997; Cruz 1992, 1998, 2001; Gonçalves y Cruz 1994; Cruz y Gonçalves 1995; Gomes 1996; Carvalho 2005). Paralela y posteriormente, se desarrollarán proyectos sobre el poblamiento prehistórico y protohistórico del Noroeste Peninsular contribuyendo, igualmente, con nuevos descubrimientos a la cuestión en análisis. Entre estos destacamos el dirigido por Domingos Cruz y Raquel Vilaça, titulado Práticas funerárias e/ou cultuais dos Finais da Idade do Bronze na Beira Alta (1993 a 1998), el coordinado por Domingos Cruz designado O Alto Paiva: sociedade e estratégias de ocupação do território desde a Pré-História Recente à Alta Idade Média (1998 a 2002) y los emprendidos por la autora: As comunidades do Bronze Final na bacia do Médio Cávado: regularidades e especificidades (1989 a 1999), A reconstitução da paisajem do Entre-Douro-e-Minho, desde meados do III a finais do II milenio $A C$-POCTI/HAR/36527/99 (2001 a 2007) y $O$ corpo na paisajem: ritos e crenças na Idade do Bronze do Noroeste Peninsular-SFRH/BSAB/ 650/06 (2007). En el curso de estos proyectos se descubrieron e inventariaron nuevos materiales y se contextualizaron y dataron radiométricamente bien nuevos sitios, bien lugares donde, en los ini- 
cios del siglo XX, se habían encontrado estructuras funerarias o evidencias que sugerían prácticas tumulares (Bettencourt 1997, 1999, 2000a, 2001, 2008, 2009c, 2010; Bettencourt y Meijide 2009; Bettencourt et al. 2002, 2003, 2005; Cruz 1997, 1999, 2001; Cruz et al. 1998a, 1998b; Cruz y Vilaça 1999; Vilaça y Cruz 1999; Dinis y Bettencourt 2004). Recientemente hay que citar el proyecto A Idade do Bronze no vale do Ave bajo la orientación de Hugo Aluai Sampaio (Sampaio et al. 2008).

Paralelamente a esta actividad se han descubierto y excavado túmulos y necrópolis, en el ámbito de la arqueología empresarial o preventiva, en otros sitios de la Edad del Bronce (Cunha 1995; Carvalho y Gomes 2000; Santos y Marques 2007; Almeida y Fernandes 2008; Almeida et al. 2008a, 2008b), frecuentemente poco estudiados o todavía inéditos, además de nuevos hallazgos aislados (M.A. Silva 1994).

En Galicia, hasta los años 1980, destacan innumerables artículos (Lopez Cuevillas 1930, 1947; Bouza Brey 1936; Lopez Cuevillas y Lorenzo Fernández 1930; Lopez Cuevillas y Lamas 1958; Taboada Chivite 1971; Delibas y Rodríguez Cabanero 1976; Ramil Soneira y Vázquez Varela 1979, entre otros) y algunas tentativas de síntesis sobre el mundo sepulcral de la Edad del Bronce, siempre basadas en hallazgos dispersos y aislados (Vázquez Varela 1988a, 1980b; Monteagudo et al. 1981). Todavía en esa década tienen lugar proyectos sobre el megalitismo que, aunque parcialmente, contribuirán con nuevos datos al conocimiento de las prácticas funerarias de la Edad del Bronce (Rodríguez Casal 1989). En

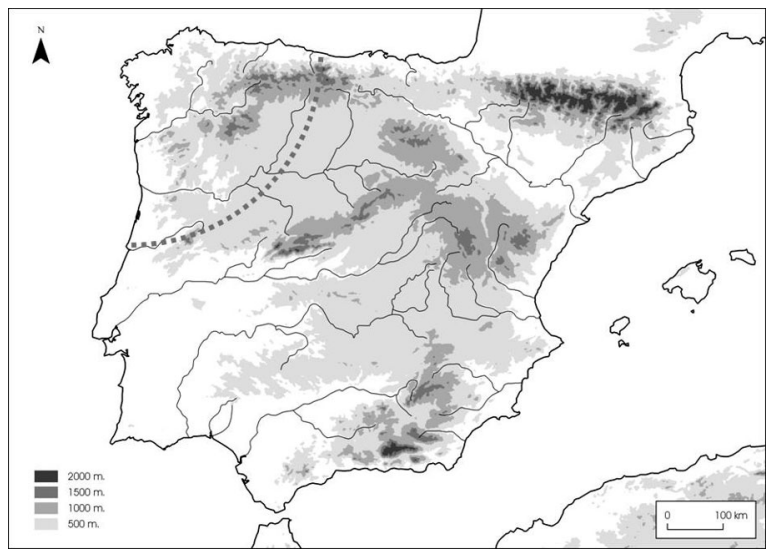

Fig. 1. Localización del área de estudio tratada en el artículo. la década de los 1990 se descubren, excavan y publican importantes estructuras sepulcrales de este período o reutilizadas en esta época (Meijide 1994, 1995, 1996; Vaquero Lastres 1995a, 1995b, Vaquero Lastres y Vázquez Collazo 1995) y se emprende el proyecto Las cistas en su entorno: estudio de una de las realidades del mundo funerario de la Edad del Bronce en Galicia-XUGA38201A95, bajo la responsabilidad de Ramón Fábregas. El conjunto de resultados obtenidos se publicó en una serie de síntesis sobre el mundo funerario de la Edad del Bronce en Galicia (Fábregas 1993a, 1993b, 1995; Fábregas y Ruiz-Gálvez Priego 1994, 1997; Fábregas y Bradley 1995, Fábregas y Penedo Romero 1995; Fábregas y Vilaseco 1998; Bóveda et al. 1999; Comendador Rey 2001). Por motivos que desconocemos, la investigación en esta región no tuvo el desarrollo que los proyectos anteriores hacían adivinar, procediendo los nuevos hallazgos sobre el tema, o sobre la Edad del Bronce en general, de actuaciones en el ámbito de la arqueología empresarial, no siempre publicados, salvo raras excepciones (Chao y Álvarez 2000; Aboal Fernández et al. 2005; Vasquez Liz 2005; Prieto- Martínez et al. 2005; Prieto-Martínez 2007; Prieto-Martínez et al. 2009a, 2009b).

En Asturias el conocimiento sobre la Edad del Bronce también es escaso, a pesar de que los nuevos proyectos centrados en los castros hayan revelado, a veces, ocupaciones de este período (Maya y Cuesta 2001; Mercadal 2001; Villa y Cabo 2003; Villa 2005). Destacan los estudios sobre algunas necrópolis megalíticas y sobre minas donde han aparecido túmulos o prácticas funerarias de la Edad del Bronce (Blas 1985, 1994, 1998, 2003, 2004, 2005). Hay, todavía, un número significativo de cuevas con enterramientos, sometidas a un notable trabajo de revisión y publicación (Arias y Armendáriz 1998; Arias y Ontañón 1999; Barroso et al. 2007a). Recientemente, a propósito de un importante enterramiento en cueva, se publicó una síntesis sobre la muerte en la Edad del Bronce de la fachada occidental de la Península Ibérica (Barroso et al. 2007b).

\section{OBJETIVOS Y PREMISAS METODOLÓGICAS}

A pesar del avance considerable que todos estos trabajos representan de cara al supuesto de 
que, a partir del Bronce Medio, la ausencia de enterramientos era la norma en la fachada atlántica de la Península Ibérica (Ruíz-Galvez 1998), fue nuestro objetivo ensayar una nueva síntesis sobre la Edad del Bronce del Noroeste. A partir de las prácticas funerarias procuramos interpretar el papel de las arquitecturas funerarias, de los contextos donde éstas se insertaron, de los adornos y de los depósitos que acompañaron a los muertos, así como del propio cadáver en la construcción, mantenimiento y transformación de la identidad social y cultural, durante la Edad del Bronce.

Para ello partimos de los presupuestos que enunciaremos. El primero es que las materialidades, en sus más diversas y amplias manifestaciones, son metáforas, simultáneamente materiales y sociales, pues derivan de acciones determinadas socialmente, a la vez que son agentes socialmente activos (Barret 2001), o sea, resultan de las relaciones sociales y contribuyen a su construcción. El segundo supuesto es que la muerte (que incluye las transformaciones de los cuerpos) y el cadáver son materialidades manipuladas y recreadas al servicio de los vivos, funcionando como un agente sea para la construcción y mantenimiento de la identidad, de las relaciones sociales y del poder, sea para su alteración. Dicho de otro modo, la muerte y las acciones que le están asociadas facilitan la implicación práctica y social de las comunidades con el mundo que las rodea. Ello se efectúa a través de los que tienen acceso al tratamiento, transformación y manipulación ideológica de los cuerpos, naturalmente, los agentes de la creación, transmisión y alteración de las relaciones de poder. El tercero es que el cadáver, las estructuras, las prácticas y el lugar de enterramiento, a través de su manipulación, ocultación, exhibición, exaltación, etc., incorporan un universo de creencias y de cosmologías (Fahlander y Oestigaard 2008).

\section{LOS DATOS}

Los contextos, las estructuras y las prácticas funerarias del Bronce Inicial y Medio del Noroeste de la Península Ibérica fueron descritos e interpretados en trabajos previos de síntesis (Bettencourt 2008, 2010) por lo que aquí resumiremos esos textos, siendo más exhaustivos en relación con los datos existentes para el Bronce Final.
Pensamos que es importante hacer explícitas las periodizaciones y taxonomías subyacentes a este trabajo dada la falta de consenso entre los arqueólogos de la región. Así, consideramos que el Bronce Inicial se habría iniciado desde el 2300/2200 AC hasta cerca del 1700/1600 AC momento, a partir del cual, comenzaría el Bronce Medio. Este concluiría a finales del II milenio AC, tal vez en torno al 1100/1000 AC. A partir de ahí se entraría en el Bronce Final cuyo término andaría por el $600 \mathrm{AC}$. Estas periodizaciones se basan, esencialmente, en los datos del Noroeste portugués y se justifican por una serie de alteraciones y continuidades verificadas en las materialidades relacionadas con estrategias de poblamiento, prácticas funerarias, producción metalúrgica y cerámica, etc., ya explicitadas (Bettencourt 2005a, 2009a, 2010).

\subsection{Reutilizaciones de las estructuras funerarias anteriores}

La reutilización de los monumentos megalíticos o de origen neolítico es un fenómeno frecuente en el Noroeste, durante todos los períodos de la Edad del Bronce. El caso más antigo del que tenemos conocimiento es el Dolmen 7 da Mourela, As Pontes, en uso entre 2457-2142 AC (Fábregas 1990/1991), seguido de Arquinha da Moura, Tondela, con ocupaciónes entre 2295-1980, 2287- 1944 y 2193-1893 AC (Cunha 1995; Cruz 2001). Durante todo el II milenio AC perduran las reutilizaciones como se puede comprobar por las fechas de la Orca da Penela 1, Tondela, entre 1943-1740 (Cruz 2001), de Madorras 1, Sabrosa, entre 1931-1696 AC (Cruz y Gonçalves 1994, 1995, Cruz 2001), de la Portela da Anta, Arouca, entre 1951-1456 (F.P. Silva 1997), del Monte da Deva 3, Gijón, entre 1885-1490 AC (Blas 2004), de Castonairas, Vila Nova de Paiva, entre 1753-1526 y 1636-1426 AC (Cruz 2001), de la Madorra da Granxa, Castro Rei, entre 1732-1531 y 1685-1531 AC (Chao Álvarez y Álvarez Merayo 2000), del Dolmen do Carvalhal, Penedono, entre 1606-1092 AC (Carvalho 2005), de la nueva ocupación de la Arquinha da Moura, Tondela entre 1416-1129 y de Ponte da Pedra, As Pontes, entre 1416-938 AC (Vaquero Lastres 1995a).

Durante el Bronce Final este fenómeno se documenta en Orca de Pedralta, Viseu, entre los si- 


\begin{tabular}{|c|c|c|c|c|}
\hline Reutilización de monumentos neolíticos & $\begin{array}{c}\text { Referencia } \\
\text { Laboratorio }\end{array}$ & Fecha BP & 2 sigma cal. & Bibliografía \\
\hline Picoto do Vasco (V. N. Paiva) & GrN-22816 & $3690 \pm 130$ & $2464-1756$ & Cruz 2001 \\
\hline Mourela 7 (As Pontes) & CSIC-977 & $3820 \pm 35$ & $2457-2142$ & Fábregas 1990/1991 \\
\hline Arquinha da Moura (Tondela) & GrA-9577 & $3740 \pm 50$ & $2295-1980$ & Cruz 2001 \\
\hline Arquinha da Moura (Tondela) & GrN-23198 & $3710 \pm 60$ & 2287-1944 & Cunha 1995; Cruz 2001 \\
\hline Arquinha da Moura (Tondela) & GrA-9255 & $3650 \pm 50$ & 2193-1893 & Cruz 2001 \\
\hline Orca 1 da Penela (Tondela) & GrN-23065 & $3510 \pm 40$ & $1943-1740$ & Cruz 2001 \\
\hline Madorras 1 (Sabrosa) & GrA-884 & $3500 \pm 40$ & $1931-1696$ & Gonçalves y Cruz 1994 \\
\hline Monte da Deva 3 (Gijón) & Beta- 12598 & $(?)$ & $1885-1490$ a) & Blas 2004 \\
\hline Portela da Anta 1 (Arouca) & $(?)$ & $3400 \pm 100$ & $1951-1456$ & F.P. Silva 1997 \\
\hline Castonairas (V.N. Paiva) & OxA-7436 & $3365 \pm 45$ & $1753-1526$ & Cruz 2001 \\
\hline Mamoas dos Prados (Arcos de Valdevez) & Ua 19729 & $3325 \pm 45$ & $1736-1501$ & $\begin{array}{l}\text { Inédita } \\
\text { (residuos orgánicos } \\
\text { procedentes de un vaso) }\end{array}$ \\
\hline Castonairas (V.N. Paiva) & OxA-7436 & $3365 \pm 45$ & $1753-1526$ & Cruz 2001 \\
\hline Madorra da Granxa (Castro Rei) & CSIC-1377 & $3346 \pm 28$ & $1732-1531$ & Chao y Álvarez 2000 \\
\hline Madorra da Granxa (Castro Rei) & CSIC-1375 & $3329 \pm 27$ & $1685-1529$ & Chao y Álvarez 2000 \\
\hline Castonairas (V. N. Paiva) & GrA-9314 & $3250 \pm 50$ & $1636-1422$ & Cruz 2001 \\
\hline Dólmen do Carvalhal (Penedono) & GrN-20792 & $3100 \pm 90$ & $1606-1092$ & Carvalho 2005 \\
\hline Arquinha da Moura (Tondela) & GrA-9575 & $3030 \pm 50$ & $1412-1129$ & Cruz 2001 \\
\hline Ponte da Pedra (As Pontes) & GrN-19216 & $2970 \pm 90$ & $1416-938$ & Vaquero Lastres 1995a \\
\hline Alto da Barreira (Coruña) & CSIC-1038 & $2840 \pm 40$ & $1127-903$ & Alonso y Bello 1997 \\
\hline Rapadouro 1 (V. N. Paiva) & GrA-9741 & $2820 \pm 50$ & $1123-843$ & Cruz y Gonçalves 1998/1999 \\
\hline Mamoa de Cabritos 1 (Baião) & GIF-7019 & $2700 \pm 60$ & 996-791 & Jorge $1988:$ nota 8 \\
\hline
\end{tabular}

Tab. 1. Cronología radiocarbónica de los monumentos megalíticos o de origen neolítico reutilizados en el Norte y Noroeste de la Península Ibérica (véase nota 3).

glos XIII y X AC (1), en Alto da Barreira, Coruña, donde el túmulo se modificó entre 1127-903 AC, en Rapadouro 1, Vila Nova de Paiva, entre 1123-843 AC (Cruz 1998: 162; Cruz y Gonçalves 1998/1999) y, probablemente, en la Mamoa de Cabritos 1, Baião, donde, en las inmediaciones de la cámara neolítica, se construyó una fosa de contorno oval conteniendo piedras y cenizas, datada entre 996-791 AC (Jorge y Vilaça 1985; V.O. Jorge 1988: nota 8), así como en el dolmen de Lordelo de Cima/Chafé, Viana do Castelo, donde se encontró un vaso carenado (2) idéntico a los exhumados en contexto doméstico, a partir del siglo XI AC. En relación con Antela da Bouça dos Córregos, Trofa y no en el Santo Tirso (en la nueva división administrativa efectuada en el Norte de Portugal), hemos observado recientemente los artefactos metálicos que, según Domingos Cruz, justificaban una reutilización en el Bronce Final. Se trata, en realidad, de piezas atribuibles a la

(1) Información inédita cedida gentilmente por Domingos Cruz.

(2) Agradecemos a Eduardo Jorge Silva haber podido observar este material.
Edad del Hierro, revelando la reocupación de este monumento con posterioridad a la Edad del Bronce (Tab. 1) (3).

En favor de la hipótesis de que estas reutilizaciones se relacionaban con prácticas funerarias hay que señalar las inhumaciones del dolmen de Arquinha da Moura, en Tondela, datadas radiométricamente en los inicios de la Edad del Bronce (Cunha 1995) y los restos óseos, presumiblemente cremados, de Orca de Pedralta, Viseu, fechados en el Bronce Final. Cuando fue posible precisar los contextos de reutilización, se verificó que los accesos primitivos no se vieron alterados, al afectar siempre los tumuli o los corredores y cámaras funerarias a través del desplazamiento de algunos pilares laterales. En los tumuli se construyeron cistas o estructuras cistoides con o sin deposición de ofrendas, como en Fonte da Malga 2, Viseu (Kalb y Hock 1979) y Arreçaio 4, Arouca donde se depositó un vasito (F.P Silva

(3) Las fechas de C14 de todas las tablas fueron calibradas con el programa OxCal4.1 y con la Curva Intcal09 disponible en http://C14.arch.ox.ac.uk/oxcal/oxCal.html, excepto las indicadas por a). En esos casos, no conocemos la fecha BP. 
1994; A.Silva 2004), hogares asociados a un nivel de piedras, como en la Madorra da Granxa (Chao Álvarez y Álvarez Merayo 2000) o fosas cubiertas con una piedra, como en Marco do Camballón 5, Vila de Cruces (Calo Lourido y Sierra Rodríguez 1983). Un ejemplo de reutilización de la cámara es la Capela da $\mathrm{Sr}^{\mathrm{a}}$ do Monte, Penedono (Carvalho 2005) y el dolmen de Picoto do Vasco/Sangrinho 4, Vila Nova de Paiva (Cruz 2000, 2001), entre otros.

Las ofrendas funerarias más comunes en estos contextos son, casi siempre, recipientes cerámicos, excepto en el Bronce Inicial donde, a veces, se acompañaron los cuerpos con ofrendas y adornos metálicos en oro, plata y cobre.

Dos de las formas cerámicas comunmente usadas en el ámbito de las prácticas funerarias del Bronce Inicial y Medio son los vasos troncocónicos y semicilíndricos presentes en numerosos dólmenes desde la Beira Alta y la Beira Litoral hasta el sur de Galicia, demostrando el elevado número de antiguos monumentos reutilizados durante estos períodos. Sin pretensión de exhaustividad citamos su hallazgo en Outeiro de Cavaladre 1, Ourense (Eguileta Franco 1999); Lordelo de Cima/Chafé, Viana do Castelo (4), en una de las Mamoas da Sierra, Esposende (Sarmento 1933); Madorras 1, Sabrosa (Gonçalves y Cruz 1994); Estante e Fonte Coberta, Alijó (V.O. Jorge 1982; Carvalho y Gomes 2000); Carvalhas Alvas, Vila Poca de Aguiar (Senna-Martínez 1989); Carapito III, Aguiar da Beira (Leisner y Ribeiro 1968; Senna-Martínez 1989); Carvalhal, Penedono (Carvalho 2005); Lameira de Cima 2, Penedono (Gomes 1996); Orcas do Tanque, Antas, Castonairas, Juncais, Vale de Cadela 1/Merouços 1 e Porto Lamoso, Vila Nova de Paiva (Leisner 1998; Senna-Martínez 1989; Cruz 2001); Orca de Seixas, Moimenta da Beira (Leisner 1998); Orca de Forles, Sátão (Moita 1966); Lapa da Orca/Fiais da Telha, Carregal do Sal (Senna-Martínez 1989); Arcainha do Seixo da Beira y Curral dos Moros/Sobreda, Oliveira do Hospital (Rocha 1899; Senna-Martínez 1989), en São Pedro Dias, Poiares; Portela da Anta 1, Arouca (A. Silva 2004) y Terranha, Sever do Vouga (Bettencourt 1982).

Otro grupo de vasos comunes en estos contextos es el de los potinhos/ púcaros similares a los designados en Galicia como vasos de tipo Tarayo con o sin asas, a veces carenados, que se dis-

(4) Inédito. Véase nota 3. tribuyen, también, desde la Beira Alta a Galicia. Sirvan de ejemplo los de Parxubeira 2, Xallas (Rodríguez Casal 1989), Madorra da Granxa, Castro Rei (Chao Álvarez y Ávarez Merayo 2000), Antela da Portelagem, Esposende (Sarmento 1933), Picoto do Vasco/ Sangrinho 4, Porto Lamoso y Orca dos Juncais, Vila Nova de Paiva (Senna-Martínez 1989; Leisner 1998; Cruz 2001), Carvalhas Alvas, Vila Poca de Aguiar (Leisner 1958), Carapito III, Aguiar da Beira (Senna-Martínez 1989), Outeiro do Rato, Carregal do Sal (Senna-Martínez 1989), Arreçaio 4, Arouca (F.P. Silva 1994; A. Silva 2004). Por la asociación de algunos de estos vasos con artefactos metálicos en cobre, por las fechas de Madorra da Granxa y por paralelos con recipientes similares encontrados en pequeños tumuli, también datados radiométricamente, sabemos que este grupo formal data del Bronce Inicial y Medio, sin que podamos excluir su anterioridad y posterioridad (Bettencourt 1997).

Durante el Bronce Medio y el Bronce Final, de 1600/1500 a 600 (Bettencourt 1997; Sampaio et al. 2008), se depositaron vasos de borde horizontal medio y ancho en antiguos monumentos megalíticos del Douro Litoral, el Minho y el sur de Galicia como en Guillar, Outeiro de Rey, Monte da Romea, Lalín (Prieto-Martínez 2007) y Lordelo de Cima/Chafé, Viana do Castelo (Silva y Marques 1986) (5). A estos períodos asociamos, igualmente, las diversas tazas carenadas halladas en dólmenes de la Beira Alta donde estas formas aparecen antes que en el Norte litoral como Sobreda, Oliveira do Hospital y Orca do Outeiro do Rato, Carregal do Sal (Senna-Martínez 1989).

Como ya indicamos los artefactos metálicos son raros y exclusivos del Bronce Inicial. Destacamos las espirales de plata encontradas en los dólmenes de la Cerca, Esposende (Jorge 1982; Almeida 1986) y de Carvalho Mau 1, Castelo de Paiva (E.J. Silva 1995); el cilindro de oro de la Mamoa 1 do Marco de Camballón, Oirós, Vila de Cruces (Bóveda 1995), una lámina perforada del dolmen de Las Llaguas, Boal (Blas 1983), una posible cuenta de collar de oro da Mamoa 1 da Chã do Brinco, Cinfães (E.J. Silva 1995) y el anillo de tiras de oro del dolmen de Mata'l Casare I, La Cobertoria, Llena (Blas 1983). Entre las piezas de cobre citaremos las hachas planas y las 
puntas de tipo Palmela de Orca de Seixas, Moimenta da Beira (Leisner 1998), el hacha del dolmen de Lobán, Vilalba (Obermaier 1923), las puntas de tipo Palmela de Parxubeira 2, Xallas (Rodríguez Casal 1989) y, particularmente, los punzones o perforadores de las Mamoas de Chafé, Viana do Castelo (Silva y Marques 1986) y de Portela da Anta 1, Arouca (F.P. Silva 1992, 1997). Subrayamos, todavía, la espiral de oro y el punzón de la Orca do Outeiro do Rato (Senna-Martínez 1989: 74-75).

\subsection{Monumentos bajo tumuli}

Otro tipo de estructuras asociadas a las prácticas funerarias de la Edad del Bronce son los monumentos bajo pequeños tumuli construidos en piedra o tierra, de planta circular, oval o semirectangular, incluyendo cistas cuadrangulares, rectangulares o poligonales, fosas ovales o semirectangulares, tapadas o no con lajas de diferentes dimensiones o simples círculos delimitados por pequeñas piedras, como en Rochão 2 (Santos y Marques 2007).

A pesar de ser bajos estos túmulos cuentan, frecuentemente, con numerosos bloques de cuarzo, granito y otras rocas locales (Cruz 1997), y se asocian con elementos naturales, como afloramientos o relieves impresionantes, características que les hacen más perceptibles en el paisaje (Cruz et al. 1998b; Vilaça y Cruz 1999).

Monumentos con cámara en fosa son las Mariolas 1, Vieira do Minho (6), Casinha Derribada 3, Viseu (Cruz et al. 1998b), Monte Calvo 2, Arouca (F.P. Silva 1997) y Reboredo 1, As Pontes (Vaquero Lastres 1995a, 1995b). A veces no aparece ninguna cámara lo que hace suponer que éstas pudieran ser de materiales perecederos o que determinados ritos se efectuaran directamente sobre el suelo. Hay también monumentos atípicos como el de Gestosinho, S. Pedro do Sul (7) que aparenta tener una cámara descentrada y definida por un círculo pétreo. En otros casos, se aprovechan las cavidades naturales existentes en los afloramientos, como en la Serra da Muna 2, Viseu (Cruz et al. 1998a).

Muchos de estos monumentos fueron construidos en la periferia o en el seno de las grandes

(6) Agradecemos esta información a la empresa ArcheoEstudios Lda.

(7) Inédito. Agradecemos la información a Alexandre Canha. necrópolis megalíticas, en territorios que habrían sido mitificados y sacralizados, por lo menos, desde el Neolítico Medio. Otros surgen en lugares nuevos sea en áreas de altitud dominante, sea en plataformas medias y bajas de las vertientes. En los últimos años, los trabajos de prospección, inventario y excavación de los monumentos funerarios en áreas amesetadas han aumentado los casos conocidos, sobre todo en la Beira Alta, en el Centro-Norte Litoral y también en el Minho, el Douro Litoral, Galicia y Asturias (Blas 1983, 1994, 2004; Cruz 2001; Santos y Marques 2007).

Seguramente del Bronce Inicial son los tumuli de Illade 3 y Reboredo 1, As Pontes, datados respectivamente entre 2474-2141 y 2471-2040 AC (Vaquero Lastres 1995a, 1995b), Meninas do Crasto 4, Baião, entre 2457-2140 AC, Serra da Muna 1 e 2, Viseu, entre 2278-2041 y 2137-1977 AC (Jorge 1983; Jorge et al. 1988; Jorge 1993; Cruz et al. 1998a), Outeiro de Gregos I, Baião, entre 2140-1786 AC (Jorge 1980) (Lám. I) y Monte da Deva 5, Gijón, entre 2135-1746 AC (Blas 2004).

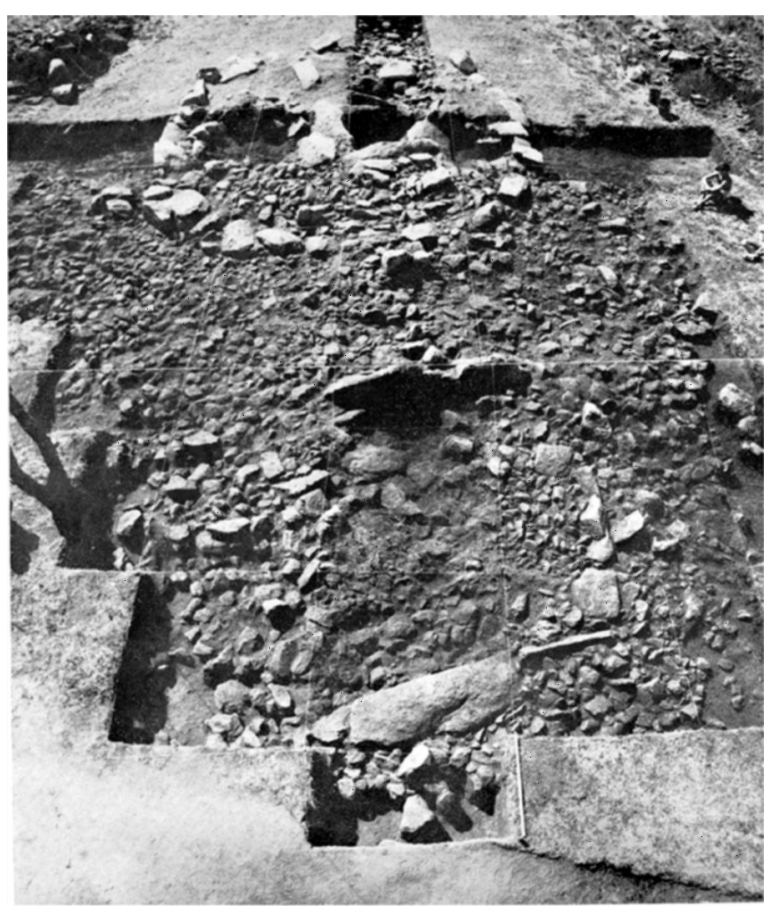

Lám. I. Pequeño tumulus de Outeiro de Gregos 1, Baião (segundo plano) y de su estructura periférica (primer plano) (según V.O. Jorge 1980). 


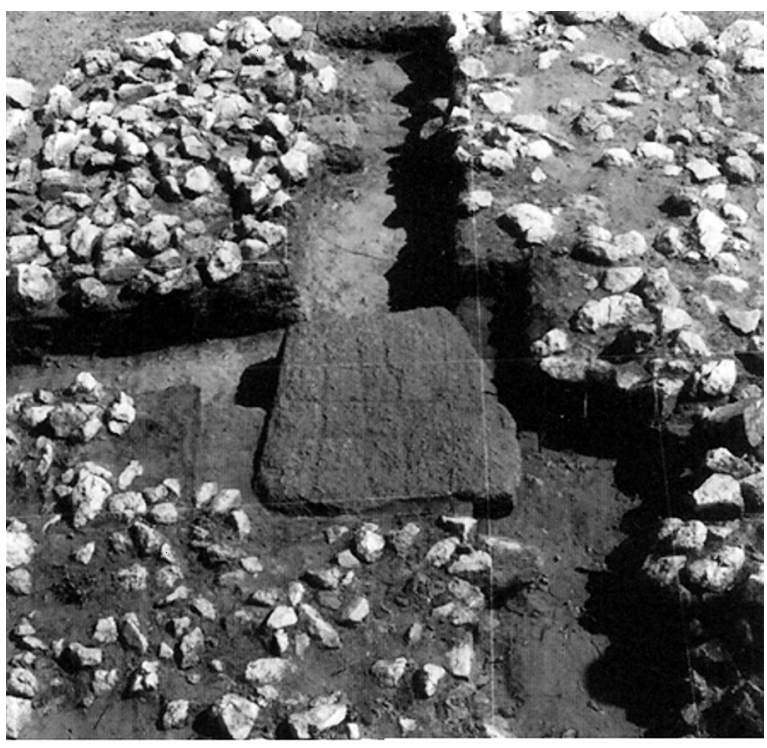

Lám. II. Pequeño tumulus da Casinha Derribada 3 (según Cruz et al. 1998b).

Al Bronce Medio asignamos la estructura periférica de Outeiro de Gregos I, Baião que revela su utilización entre 1768-1517 AC (Jorge 1980), probablemente la construcción de Piedrafita 5, Las Regueras, entre 1741-1056 AC (Blas 1985), Outeiro de Gregos 5, Baião, entre 1668-1416 AC (Jorge et al. 1988; Jorge 1993; Cruz 1992) y la Casinha Derribada 3, Viseu, datada entre 14201132 AC (Cruz et al. 1998b) (Lám. II). A finales del Bronce Medio, entre 13181-1131 AC, corresponde el monumento de la $\mathrm{Sr}^{\mathrm{a}}{ }^{\mathrm{a}}$ da Ouvida 7 , Castro Daire, inserto en un conjunto tumular que perdura hasta momentos avanzados del Bronce Final, como se puede comprobar por los de la $\mathrm{Sr}^{\text {a }}$ da Ouvida 11 y 12, Castro Daire, datados entre 1026-913 y 927-829 AC, respectivamente (Cruz y Vilaça 1999). En el conjunto, carente de cámaras pétreas, los ritos de fuego fueron significativos, demostrando, más bien, acciones ceremoniales en el contexto de las prácticas funerarias, entre otras (Cruz y Vilaça 1999) (Fig. 2).

Al Bronce Final se ha atribuido, igualmente, el monumento bajo tumuli de la Fonte da Malga 1, Viseu (Kalb y Hock 1979; Kalb 1994; Vilaça y Cruz 1999) aunque los fragmentos cerámicos que sirvieron para datarlo no sean, en nuestra opinión, determinantes, pudiendo este tumulus así como los restantes existentes en el área, integrarse en cualquier período de la Edad del Bronce (Tab. 2).

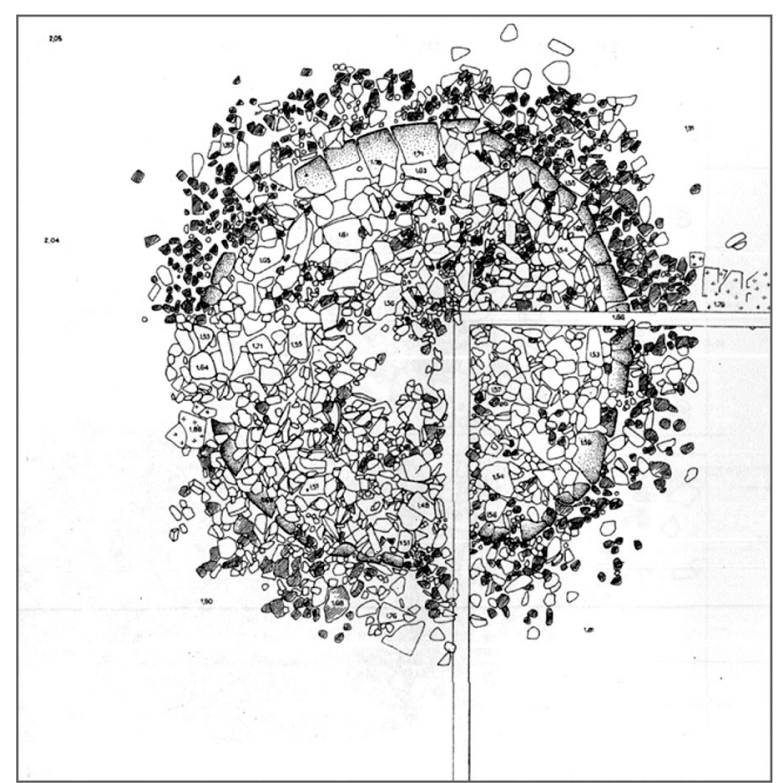

Fig. 2. Pequeño tumulus de la Sr. ${ }^{a}$ da Ouvida 7, Castro Daire (según Cruz y Vilaça 1999).

A pesar de que las ofrendas y los adornos nunca fueron muy abundantes en este tipo de estructuras, se conocen en algunos tumuli. Para el Bronce Inicial destacamos los artefactos de excepción del túmulo 240 de la Veiga dos Moros/Vilavella, As Pontes (recientemente reinterpretado como tal monumento) donde apareció una diadema de oro, un puñal de lengüeta y cuatro puntas de Palmela (Maciñeira 1941; Fábregas y Vilaseco 1998); la punta de tipo Palmela, el brazal de arquero y el vaso troncocónico de Chã de Arefe 1 y el brazal de arquero de Chã de Arefe 2, Barcelos (cistas atípicas rodeadas por bloques graníticos) (A.C.F. Silva et al. 1981) (8); las espirales de plata de Outeiro de Gregos 1 y de Meninas do Crasto 4, Baião (Jorge 1980, 1983) y el hacha plana de Los Fitos, Llena-Quirós (Blas 1983, 1994). A este período cronológico-cultural podemos todavía atribuir los vasos troncocónicos de Serra da Muna 2, Viseu y los fragmentos de molinos manuales depositados en el tumulus de Serra da Muna 1 (Cruz et al. 1998a). Bien al Bronce Inicial bien al Medio pudo pertenecer el vaso troncocónico de Rapadoro 2, Vila Nova de Paiva

(8) A pesar de que sus excavadores no consideraron la existencia de tumuli sobre estas cistas el hecho de que estuvieran rodeadas por bloques graníticos y bajo una capa de sedimentos nos lleva a plantear la hipótesis de que pudieran tener apenas un tumulus de tierra. 


\begin{tabular}{|c|c|c|c|c|}
\hline Monumentos bajo tumuli & $\begin{array}{c}\text { Referencia } \\
\text { Laboratorio }\end{array}$ & Fecha BP & 2 sigma cal. & Bibliografía \\
\hline Illade 3 (As Pontes) & GrN-19213 & $3855 \pm 60$ & $2474-2141$ & Vaquero Lastres 1995b \\
\hline Reboredo 1 (As Pontes) & GrN-19214 & $3820 \pm 70$ & $2471-2040$ & Vaquero Lastres 1995b \\
\hline Meninas do Crasto 4 (Baião) & Media Pond & $3815 \pm 36$ & $2457-2140$ & $\begin{array}{l}\text { Jorge 1983; Jorge et al. } \\
\text { 1988; Jorge } 1993\end{array}$ \\
\hline Serra da Muna 1 (Viseu) & GrN-24056 & $3750 \pm 25$ & $2278-2041$ & Cruz et al. 1998a \\
\hline Serra da Muna 2 (Viseu) & Media Pond & $3671 \pm 22$ & 2137-1977 & Cruz et al. 1998a \\
\hline Outeiro de Gregos I (Baião) & CSIC-772 & $3620 \pm 50$ & $2140-1786$ & Jorge 1980 \\
\hline Monte da Deva 5 (Gijón) & Beta-165947 & $3580 \pm 70$ & $2135-1746$ & Blas 2004 \\
\hline $\begin{array}{l}\text { Outeiro de Gregos I (Baião) (estructura } \\
\text { periférica) }\end{array}$ & CSIC-771 & $3360 \pm 50$ & $1768-1517$ & Jorge 1980 \\
\hline Piedrafita 5 (Las Regueras) & Ly-2939 & $3160 \pm 130$ & $1741-1056$ & Blas 1985 \\
\hline Outeiro de Gregos 5 (Baião) & CSIC-773 & $3250 \pm 60$ & $1668-1416$ & Jorge et al. 1988; Jorge 1993 \\
\hline Casinha Derribada 3 (Viseu) & Media Pond & $3045 \pm 46$ & $1420-1132$ & Cruz et al. $1998 \mathrm{~b}$ \\
\hline Sr. ${ }^{\text {a da Ouvida }} 7$ (C. Daire) & Media Pond & $3010 \pm 27$ & $1381-1131$ & Cruz y Vilaça 1999 \\
\hline Sr. $^{\text {a }}$ da Ouvida 11 (C. Daire) & Media Pond & $2822 \pm 20$ & $1026-913$ & Cruz y Vilaça 1999 \\
\hline Sr. ${ }^{\text {a }}$ da Ouvida 12 (C. Daire) & Media Pond & $2742 \pm 21$ & $927-829$ & Cruz y Vilaça 1999 \\
\hline Piedrafita 5 (Las Regueras) & UGRA-191 & $2610 \pm 110$ & $978-411$ & Blas 1985 \\
\hline
\end{tabular}

Tab. 2. Cronología radiocarbónica de los monumentos bajo tumuli en el Norte y Noroeste de la Península Ibérica (véase nota 3).

(Cruz 2001) y el semicilíndrico de Domingueiros/Matas 2, Vila Nova de Paiva (Leisner 1998; Cruz 2001). Al Bronce Medio cabe asignar los vasos similares a los de tipo Taraio y las tazas carenadas con borde reentrante de la Casinha Derribada 3, Viseu (Cruz et al. 1998b) y a esta cronología o al Bronce Final la taza carenada de pasta fina del Monte Calvo 2, Arouca, referida por F.P. Silva (1997). Admitimos, igualmente, que el Rochão 2, Castro Daire, pueda ser del Bronce Final (Santos y Marques 2007), no sólo por las justificaciones presentadas por sus excavadores, sino también por la presencia de una pesa de telar sobre canto rodado - un artefacto tradicionalmente conectado con contextos residenciales e innovador en contextos tumulares, una característica que se evidenciará en este período, como veremos en el punto 4 de este texto.

\subsection{Cistas}

Las cistas rectangulares, trapezoidales o cuadrangulares y las estructuras cistoides, en esquisto o granito, cubiertas con lajas o piedras, sin $t u-$ muli, son otro tipo de construcciones asociadas a prácticas funerarias de larga duración, persistiendo desde el Calcolítico hasta el Bronce Final, pudiendo contener inhumaciones o incineraciones. Se distribuyen, normalmente, en áreas conectadas con valles fértiles, a veces, en el interior de los poblados coetáneos.

Para el Bronce Inicial, entre 2109-1755 AC, destacamos la cista de la Quinta de Água Branca, en Vila Nova de Cerveira, donde un individuo adulto, posiblemente de sexo masculino (9) fue inhumado con una diadema de oro sobre el cráneo, un puñal de lengüeta a la altura de la cintura, un par de espirales y dos aros de oro en posición indeterminada (Fortes 1906).

Otro ejemplo significativo es la necrópolis de Lagares, Macedo de Cavaleiros. Aquí habrían aparecido varias sepulturas de inhumación formadas por lajas de esquisto. Se conoce la descripción de una con 1,80 $\mathrm{m}$ de longitud, $1 \mathrm{~m}$ de anchura y $1 \mathrm{~m}$ de profundidad. En su interior se detectaron fragmentos cerámicos y una espiral de oro lo que permite datar este lugar en el Bronce Inicial (Alves 1975; Cruz 2000).

Otra necrópolis importante es la de Atios/Budiño, Porriño, descubierta en la llanura aluvial del río Loro. La única cista intacta tenía forma rectangular y orientación Este-Oeste. En la esquina noreste estaban colocados una piedra de cuarzo, dos puñales de lengüeta de dimensiones distintas, dos cilindros de oro y dos espirales de plata, encontrándose una de ellas casi destruida. En los

(9) Agradecemos a Eugénia Cunha de la Universidad de Coimbra la revisión de los huesos. 
aplanamientos de tierras efectuados en el local fueron detectadas varias lajas graníticas pertenecientes a otras sepulturas (Álvarez Blázquez et al. 1970).

Una situación similar parece haber experimentado la necrópolis de Chedeiro, A Pedrosa, Cualedro, descubierta en terrenos agrícolas y en las cercanías de un poblado, una de cuyas sepulturas contenía una espiral de plata. En las inmediaciones aparecieron otras tres cistas una con tres vasos troncocónicos, otra con dos vasos similares a los de Taraio, uno de cuello alto tipo jarra y otro troncocónico (Taboada Chivite 1971; Delibes de Castro y Rodríguez Colmenero 1976; Vázquez Varela 1980a).

Necrópolis paralela, según nuestras investigaciones en el sitio, es la de Agra da Ínsua, en los límites de Piedra Figueira con Piedra Marrada, Carnota, a pocos metros de la margen izquierda del río Durán. Aquí se hallaron tres cistas, orientadas de Norte a Sur y distantes entre sí de 6 a $7 \mathrm{~m}$. La más intacta contenía un puñal de lengüeta, un brazal de arquero y restos de huesos (Luengo y Martínez 1965).

Igualmente importante es la necrópolis de Gandón, Cangas de Morrazo, localizada en tierras de buen potencial agrícola. Constaba de dos cistas: la 1, de reducidas dimensiones es de planta trapezoidal, con restos de una cremación y la 2 , mayor, con la laja de cubierta grabada con cazoletas. Entre las tierras sueltas del relleno de la segunda había pequeñísimos fragmentos de cerámica y el depósito de un brazal de arquero y de una punta de tipo Palmela, en el fondo. En el espacio circundante aparecieron dos molinos de mano lo que, junto con los fragmentos del relleno del túmulo 2, permitió a A. de la Peña (1985) plantear que hubiera un poblado en las inmediaciones.

Aunque desconocemos si estaban integradas en una necrópolis, cabe citar, todavía, las cistas del Bronce Inicial de Taraio, Malpica, de cerca de $1,11 \mathrm{~m}$ de longitud, $94 \mathrm{~cm}$ de anchura y $72 \mathrm{~cm}$ de profundidad, cuyas ofrendas consistían en un artefacto lítico, un puñal de lengüeta y un vasito (Rodríguez Gras 1974; Vázquez Varela 1980a); la cista de Fariñas, Santa Comba, en cuyo interior estaba depositado un puñal de lengüeta (Vázquez Varela 1980a); la cista de As Antas, Rodeiro, con una de las losas grabadas con un reticulado incompleto y conteniendo un puñal de lengüeta y un vasito (Vázquez Varela 1980b; Monteagudo et al. 1981).
Al mismo período cronológico se podrían atribuir las cistas de Coitemil, Agolada (Vázquez Varela 1980b; Monteagudo et al. 1981) y la de A Insua, en las inmediaciones del dolmen de Dombate ambas con lajas grabadas con motivos lineares, triangulares, en zig-zag y cazoletas (Vázquez Varela 1980b), con paralelo en la cista de Antas, Rodeiro y en la orfebrería de este período (véanse Monteagudo et al. 1981; Ladra 2003).

Los límites cronológicos de los vasos troncocónicos nos sirven para insertar, entre el Bronce Inicial y el Bronce Medio, una serie de cistas y de necrópolis en que aparecen. Nos referimos, en Portugal, a las cistas de la Lomba (Fontela de Godim), Vila da Ponte, Montalegre (Sanches 1980; M.A. Silva 1994; Baptista 1999; Bettencourt 2009c); la necrópolis de las Cabriadas/Gorgolão, también en Vila da Ponte, Montalegre, localizada en una pequeña elevación sobre el valle del Rabagão, en la que se encontraron tres sepulturas, no lejos de campos agrícolas (Sanches 1980; M.A. Silva 1994; Baptista 1999; Bettencourt 2009c); la de Lordelo, contigua al dolmen de Chafé, Viana do Castelo que contenía un canto rodado y un vaso troncocónico (Silva y Marques 1984); la necrópolis da Cavaleira, Esposende, en plena plataforma litoral, donde, en una de las sepulturas de piedra en "forma cubeta rectangular", yacía un vaso troncocónico, liso con asa (Leisner 1958; Almeida 1988), la presumible necrópolis de Agra das Canas/Campo de Valinhos, Medas, Gondomar (Jorge 1982: 506-507). A este mundo hay que atribuir, igualmente, el vaso troncocónico asociado a lajas de esquisto, insertado en el recinto monumentalizado del Castêlo, Sedrim, Sever do Vouga (Bettencourt 1988).

Del Bronce Medio es la cista de A Forxa, Riós, datada entre 1756-1527 AC, en cuyo interior había cuatro vasos troncocónicos (Méndez Fernández 1995 in Fábregas y Vilaseco Vázquez 1998; Prieto Martínez et al. 2009) (Fig. 3).

También de este período genérico son las estructuras cistoides, halladas en la periferia occidental del poblado de Sola IIb, Braga, construidas con pequeños bloques graníticos y una laja colocada al Este, cubiertas con montículos de piedra, que interpretamos como eventualmente funerarias dadas las especificidades del lugar en el contexto del poblado. Se datan entre 1690-1500 AC (Bettencourt 1997, 1999, 2000b).

Todavía del Bronce Medio podría ser la necrópolis de cistas de Lugar de Belinho (parroquia de 


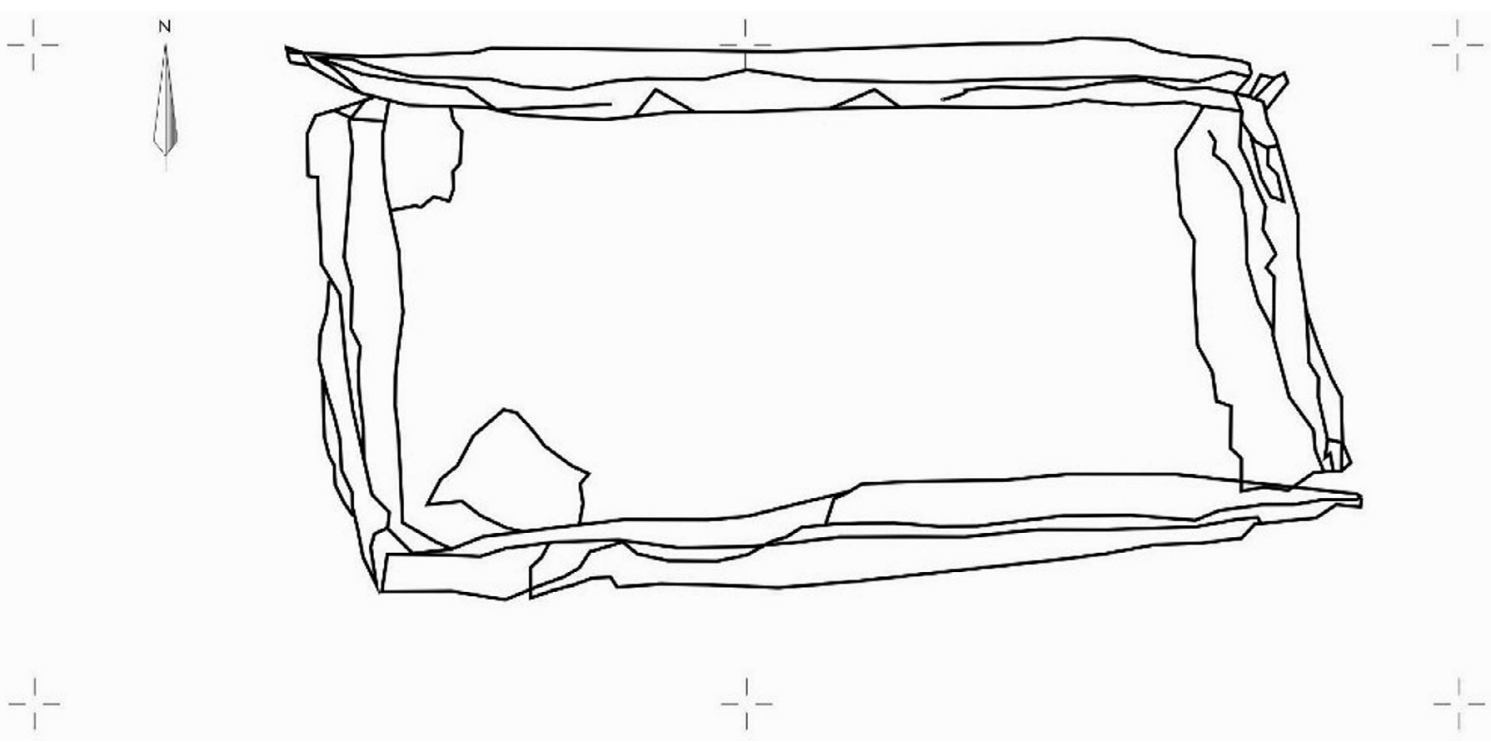

Fig. 3. Cista de A Forxa, Riós. La distancia entre crucetas es de 1 m (según Prieto Martínez et al. 2009a).

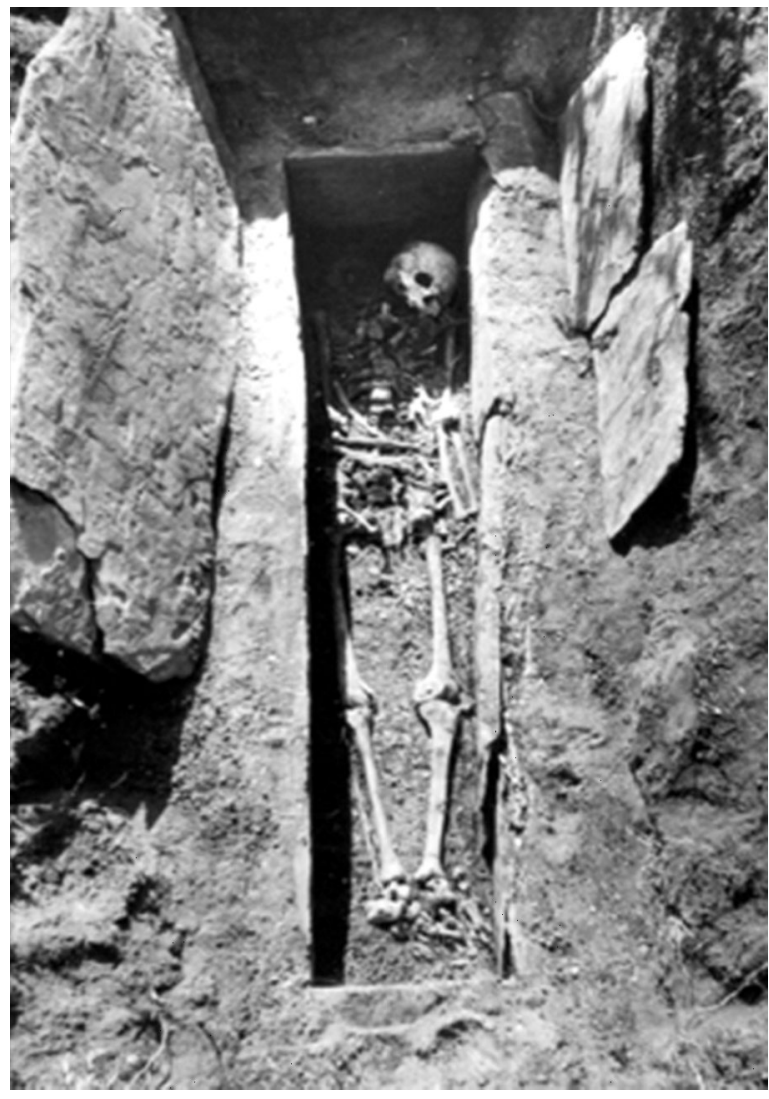

Lám. III. Cista de la necrópolis de Agra de Antas, Esposende (foto Museu da Faculdade de Ciências do Porto).
S. Paio de Antas, Esposende), situada en una plataforma baja de una colina elevada sobre la plataforma litoral, no lejos de un poblado. Allí, habrían aparecido varias sepulturas en esquisto, en cuyo interior se depositaron vasos de ancho borde horizontal (Almeida 1986; Soeiro 1988) y de tipo Taraio, similares a los encontrados en Casinha Derribada 3 datados entre 1420-1132 AC (Bettencourt 1999).

En la necrópolis de Agra de Antas (en la misma parroquia) localizada en un área elevada sobre tierras agrícolas ya con más de 14 sepulturas identificadas de dimensiones diversas, se recogieron huesos de varios individuos (Lám. III). Las sepulturas contenían vasos de ancho borde horizontal, así como uno semicilíndrico (Ataíde y Teixeira, 1940; Soeiro 1988, Almeida 1989). Esta necrópolis se fecha entre 1406-1132 AC (Cruz y Gonçalves 1998/1999; Bettencourt 1999).

Ya del Bronce Final es la necrópolis de cistas rectangulares de Monte da Ola, Vila Fria, Viana do Castelo, donde se detectaron, por lo menos, tres cistas datadas, entre 1251-938 AC (Dinis y Bettencourt 2004).

Entre 1189-1008 AC se fecha el recinto de seis pequeñas cistas cuadrangulares de Paranho, Viseu, con cremaciones dentro de vasos o directamente en las estructuras pétreas (Cruz 1997, 1999) (Fig. 4). La misma cronología genérica se atribuyó al monumento similar de Travessa da 


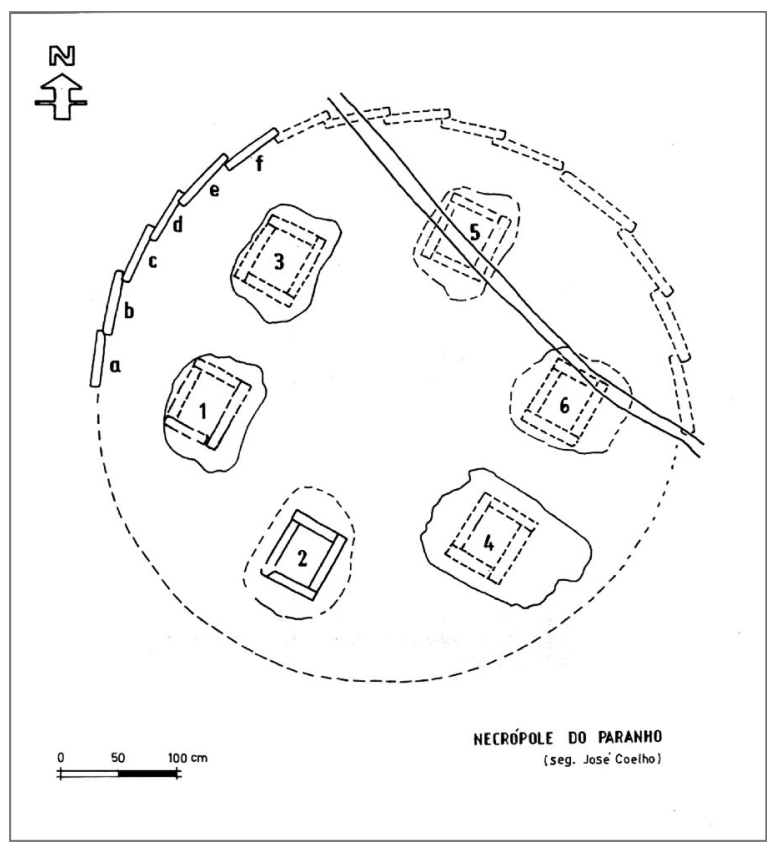

Fig. 4. Conjunto de cistas de Paranho, Viseu (según Cruz 1997).

Lameira de Lobos, Castro Daire (Cruz y Vilaça 1999; Cruz 2001), aunque las dataciones de radiocarbono lo sitúan en la Edad del Hierro (Santos y Marques 2007: 40) (Tab. 3).

Al Bronce Final debería pertenecer la cista rectangular de Curvos, Esposende, donde se exhumó un vaso de carena alta, pulido, de fondo plano y pasta arenosa/micácea (Soeiro 1988), forma típica del Bronce Final en el Noroeste por- tugués (Bettencourt 2000b) y la pequeña cista semicuadrangular encontrada en el interior del

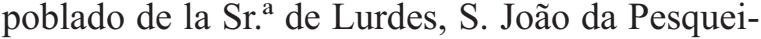
ra, datado en este período genérico (Carvalho y Gomes 2002/2003). Por la misma asociación de ideas es posible que cupiera relacionar con el mundo funerario-cultual la estructura cistoide del poblado de Santinha, Amares, cubierta de piedras y conteniendo un vasito con restos de hollín, datada entre 1016-810 AC. Esta construcción, localizada en la vertiente oriental del poblado, en las inmediaciones de un afloramento granítico en parte tallado, se insertaría en un área donde se depositaron otros vasitos con vestigios de hollín y una gran olla conteniendo fragmentos de pino quemado, especie que, además de muy rara en la época, al arder, dejaría un olor agradable e intenso. Este conjunto de particularidades hace excepcional este lugar en el interior del poblado (Bettencourt 1997, 2001).

Seguramente de carácter funerario-religioso es la pequeña cista cuadrangular situada en la entrada del presumible recinto ceremonial de Chao Samartín, Grandas de Salime, donde se depositó una bóveda craneal femenina, datada entre 805-540 AC (Villa y Cabo 2003) (Lám. IV).

Pero, además de estas estructuras, hay otras cistas o necrópolis cuyos datos apenas permiten su integración genérica en la Edad del Bronce. Es el caso de O Cubillón, Xermade, Lugo, que contenía restos de huesos de adulto en un vasito (Ramil Soneira y Vázquez Varela 1979; Vázquez Varela 1980), de Biobra, O Barco de Valdeorras (Caamaño 2007: 83), de la cista de los Juncais,

\begin{tabular}{|l|l|l|l|l|}
\hline \multicolumn{1}{|c|}{ Cistas y estructuras cistoides } & $\begin{array}{c}\text { Referencia } \\
\text { Laboratorio }\end{array}$ & Fecha BP & 2 sigma cal. & \multicolumn{1}{c|}{ Bibliografía } \\
\hline $\begin{array}{l}\text { Agro de Nogueira (Melide) } \\
\text { Quinta Água Branca (V. N. Cerveira) }\end{array}$ & $\begin{array}{l}\text { Beta-231718 } \\
\text { Beta-230330 }\end{array}$ & $\begin{array}{l}3930 \pm 40 \\
3570 \pm 50\end{array}$ & $\begin{array}{l}2566-2294 \\
2109-1755\end{array}$ & $\begin{array}{l}\text { Bettencourt y Meijide 2009 } \\
\text { Inédita } \\
\text { (huesos humanos) }\end{array}$ \\
A Forxa (Riós) & Ua-21691 & $3370 \pm 44$ & $1756-1527$ & $\begin{array}{l}\text { Prieto Martínez et al. 2009a } \\
\text { Sola IIb (Braga) }\end{array}$ \\
Agra de Anta (Esposende) & UtC-4785 & $3315 \pm 40$ & $1690-1500$ & Bettencourt 1997; 1999; 2000b \\
Monte da Ola (Viana do Castelo) & Media Pond & $3028 \pm 40$ & $1406-1132$ & Bettencourt 1999 \\
Paranho (Viseu) & Beta -188258 & $2890 \pm 40$ & $1251-938$ & Dinis y Bettencourt 2004 \\
Santinha (Amares) & Media Pond & $2895 \pm 19$ & $1189-1008$ & Cruz 1997, 1999 \\
Chao Samartín (G. de Salime) & CSIC-1085 & $2761 \pm 50$ & $1016-810$ & $\begin{array}{l}\text { Bettencourt 1997, 2001 } \\
\text { Villa y Cabo 2003 } \\
\text { Chao Samartín (G. de Salime) }\end{array}$ \\
\hline
\end{tabular}

Tab. 3. Cronología radiocarbónica de las cistas y estructuras cistoides en el Noroeste de la Península Ibérica (véase nota 3). 


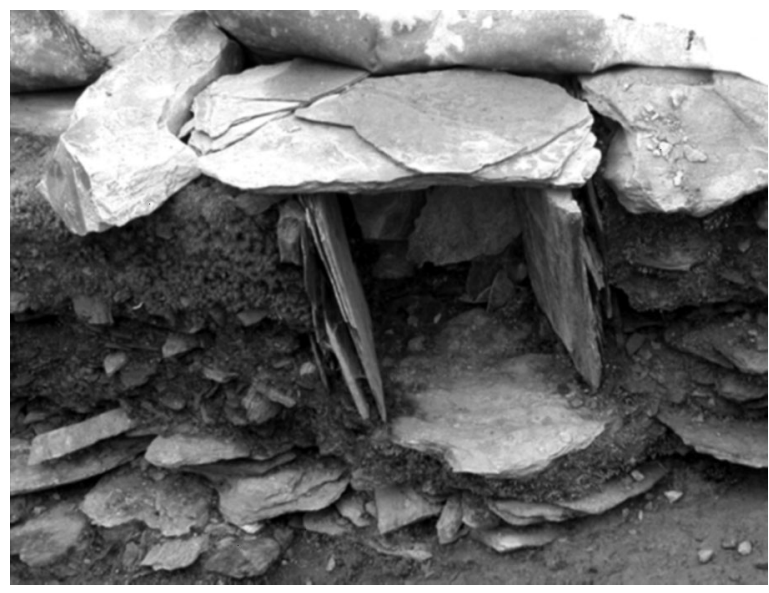

Lám. IV. Cista de Chao Samartín, Grandas de Salime (según Villa y Cabo 2005).

Vila Pouca de Aguiar (Cruz 2001) y de la necrópolis de Bicos do Lago, Muros, recientemente excavada (Lám. V) (10).

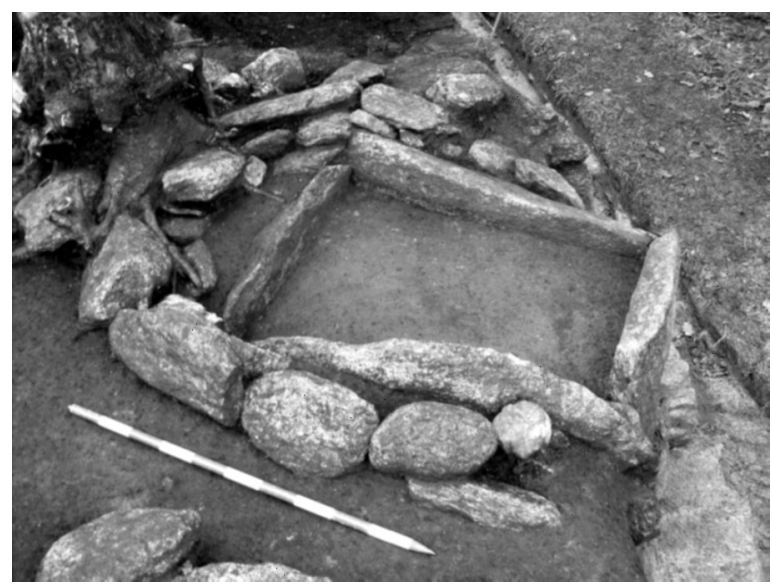

Lám. V. Cista de Bicos do Lago, Muros (foto M. ${ }^{\mathrm{a}}$ José Bóveda Fernández).

\subsection{Sepulturas simples}

Otras estructuras tumulares usadas durante la Edad del Bronce son las sepulturas simples, de forma oval o rectangular, excavadas en el substrato rocoso, a veces cubiertas por una potente capa

(10) Inédito. Agradecemos a M. ${ }^{a}$ José Bóveda Fernández la consulta del texto Traballos de Recuperación e Escavación no Contorno da Posible Cista de Bicos do Lago, Abelleira, situada no Concello Muros, A Coruña, entregado para su inclusión en el libro de resúmenes de los trabajos arqueológicos de 2008, a publicar por la Xunta de Galicia.

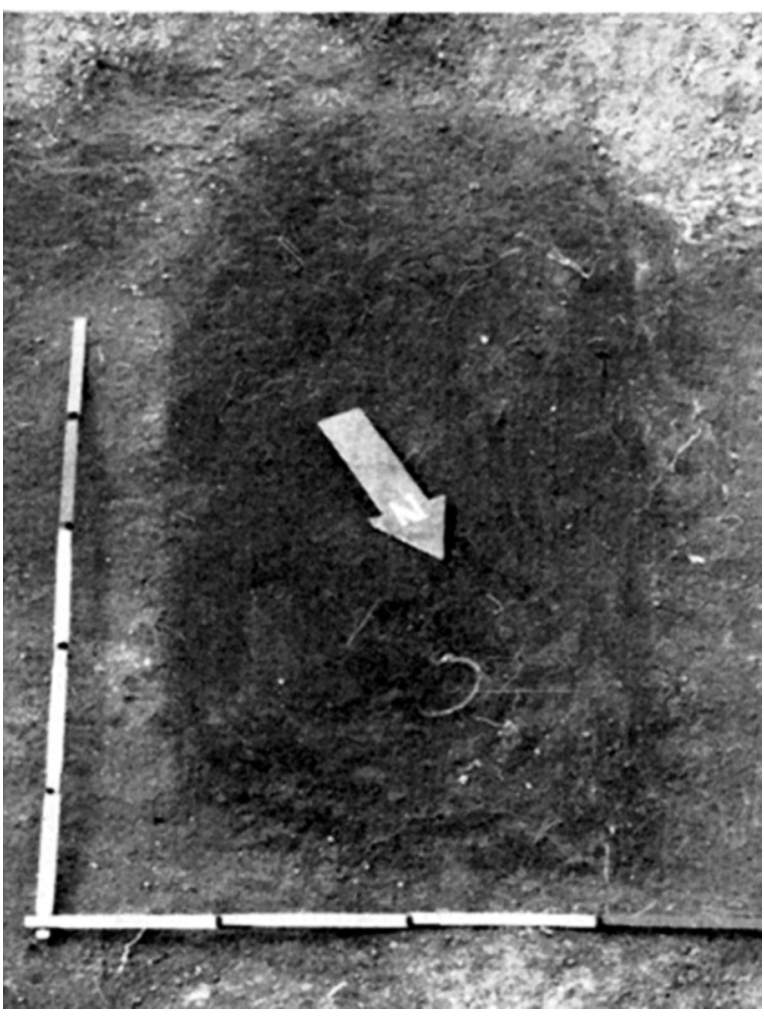

Lám. VI. Sepultura simples de la necrópolis do Tapado da Caldeira, Baião (según S.O. Jorge1980a, 1980b).

de arcilla o con pequeñas concentraciones de piedra. Sin ofrendas o conteniendo sólo recipientes cerámicos estas sepulturas se distribuyen en territorios conectados con valles fértiles, frecuentemente cerca de poblados.

Se conocen, por lo menos, a partir del Bronce Medio como se puede verificar en la necrópolis de Tapado da Caldeira, Baião (Lám. VI) en las cercanías de Bouça do Frade, datada entre 1617-1437 AC (Jorge 1980a, 1980b, 1983, 1985). En este período deberían integrarse muchas de las sepulturas con vasos troncocónicos de la gran necrópolis de Cimalha, Felgueiras, contigua a un poblado que suponemos coetáneo (Almeida y Fernandes 2008; Almeida et al. 2008a) (Lám. VII). Esta propuesta cronológica tiene en cuenta los niveles de ocupación del poblado con formas cerámicas afines a las de Sola II, en Braga (de la primera mitad del II milenio AC) y un molde doble, en piedra, para hachas del tipo Bujões/Barcelos (Bettencourt 2009a) (11).

(11) Agradecemos a Francisco Queiroga la posibilidad de ver estos materiales. 


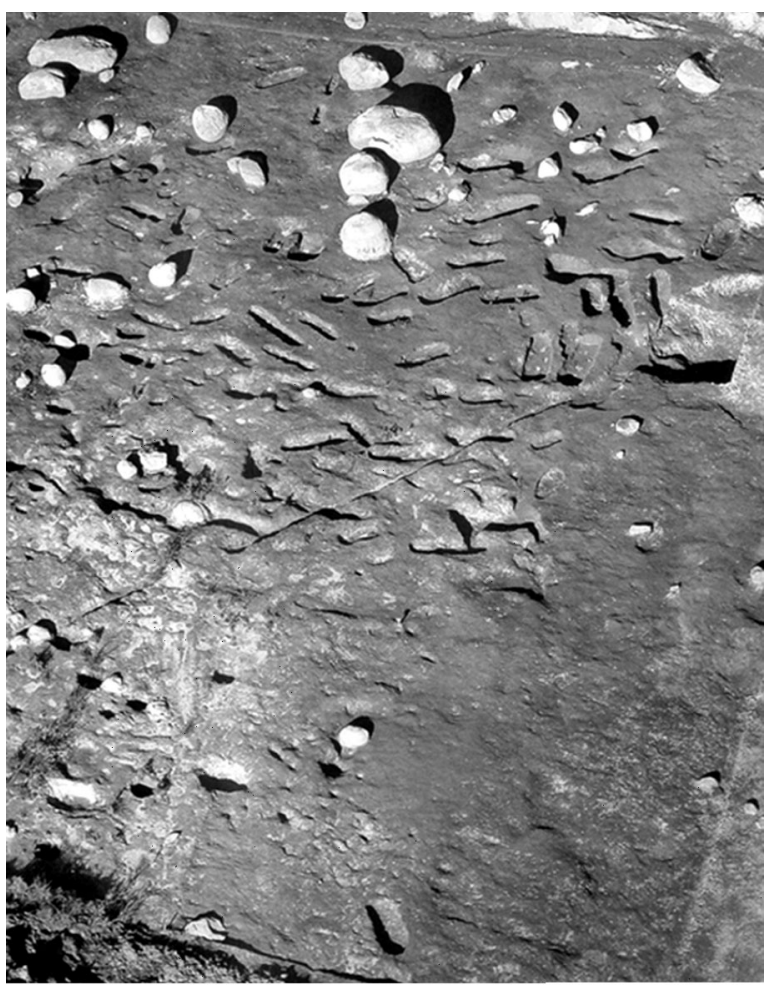

Lám. VII. Necrópolis de sepulturas simples da Cimalha, Felgueiras (foto P.B. Almeida, adaptada).

Son conocidas otras necrópolis de sepulturas simples en el Noroeste, cuyo conjunto artefactual apunta al Bronce Medio. A título de ejemplo referimos la de Alto da Vela/Gulpilhares, Vila Nova de Gaia de donde procederían, al menos, un vaso semicilíndrico, otro troncocónico y un tercero de ancho borde horizontal (Fortes 1909; Guimarães 1983; A.C.F. Silva 1993; Lobato 1995). Lo mismo se podría pensar de la necrópolis de Coto da Laborada, Calvos de Randín, localizada en una vertiente suave y definida por dos grupos de sepulturas donde coexistían los vasos troncocónicos con otros de ancho borde horizontal (López Cuevillas 1930, 1947; López Cuevillas y Lorenzo Fernández 1930).

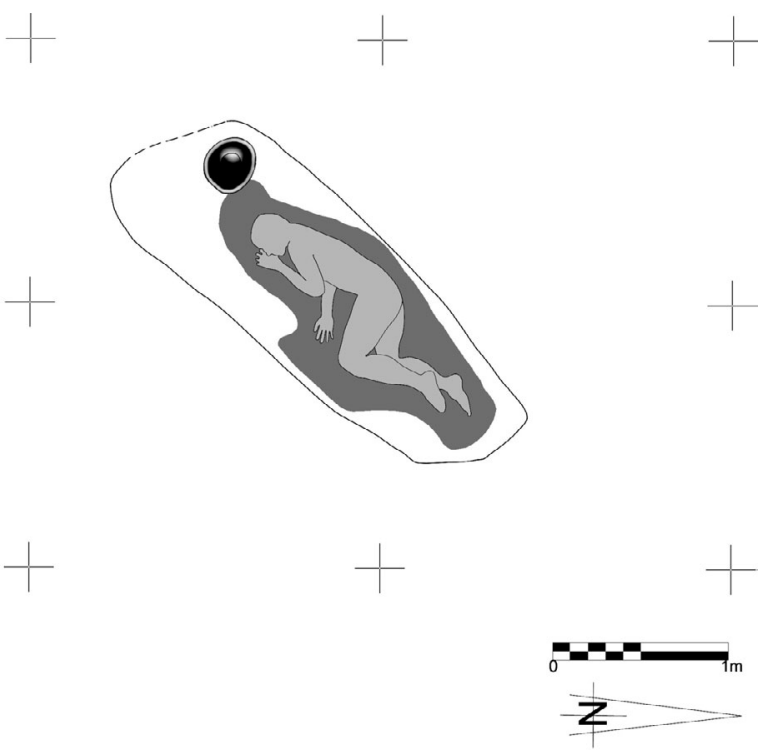

Fig. 5. Reconstitución de una de las sepulturas del Pego a partir de la estratigrafía (según Bettencourt 2010. Diseño de Jorge Guedes).

Al Bronce Final pertenece la necrópolis de inhumación de Pego, Braga, inserta en el poblado del mismo nombre y donde se excavaron más de 12 sepulturas, casi todas con vasos de ancho borde horizontal (Fig. 5). De destacar que una de ellas contenía una pesa de telar sobre canto rodado y una fusayola. La fecha de radiocarbono, obtenida a partir de un tronco de la empalizada que delimita todo el poblado y la necrópolis, sitúa esta estación entre 804-419 AC (Sampaio et al. 2008; Bettencourt 2009a).

Se conocen otras necrópolis de sepulturas simples de cronología más indefinida, como la de Monte de Mesiego, O Carballiño (Lopez Cuevillas y Lamas 1958) que creemos organizada en núcleos, eventualmente cerca del hábitat, dada la inclusión de fragmentos cerámicos, muy pequeños, en el relleno de las sepulturas (Tab. 4).

\begin{tabular}{|l|l|l|l|l|}
\hline \multicolumn{1}{|c|}{ Sepulturas simples } & \multicolumn{1}{|c|}{$\begin{array}{c}\text { Referencia } \\
\text { Laboratorio }\end{array}$} & Fecha BP & 2 sigma cal. & \multicolumn{1}{c|}{ Bibliografía } \\
\hline $\begin{array}{l}\text { Tapado da Caldeira (Baião) } \\
\text { Pego (Braga) }\end{array}$ & $\begin{array}{l}\text { Media pond. } \\
\text { Beta - 230328 }\end{array}$ & $\begin{array}{l}3250 \pm 40 \\
2530 \pm 50\end{array}$ & $\begin{array}{l}1617-1437 \\
804-419\end{array}$ & $\begin{array}{l}\text { Jorge 1980a, 1980b, 1983, 1985 } \\
\text { Sampaio et al. 2008 }\end{array}$ \\
\hline
\end{tabular}

Tab. 4. Cronología radiocarbónica de las sepulturas simples en el Noroeste de la Península Ibérica (véase nota 3). 


\subsection{Fosas abiertas en el sustrato rocoso}

Debido a la acidez de los suelos del Noroeste de la Península Ibérica es difícil comprender la función de las fosas abiertas en la arcilla. Sin embargo es probable que muchas pudiesen haberse usado como sepulcros, desde el Bronce Inicial. Esta hipótesis se basa en la existencia de huesos humanos en una de las fosas de Fraga do Zorro, Verín, datada entre 1882-1639 AC (Fábregas 2001; Prieto Martínez et al. 2009a). Algunas fosas estaban selladas por acumulaciones de piedras (Prieto Martínez et al. 2009b), sugiriendo su posible carácter de depósito cultual, aunque dudamos si considerar la totalidad del sitio como una necrópolis a tenor de las características de sus estructuras y de todo el conjunto cerámico.

Este hallazgo ha permitido revaluar algunos contextos en fosa existentes en la región. Nos referimos, por ejemplo, a las dos fosas de las Boucinhas, Ponte de Lima, contiguas a un poblado y datadas entre 2294-1980 AC, que contenían recipientes cerámicos enteros (Almeida et al. 1994) (Fig. 6). Es de destacar que todos los vasos exhumados presentaban vestigios parciales de hollín en las caras externas e internas, situación recu- rrente en los vasos sepulcrales (Bettencourt et al. 2004).

La fosa encontrada en la base de Cameixa, Ourense, también fue interpretada como sepulcral. Aquí, en 2341-2040 AC, se depositó un vaso entero con restos de pequeños carbones, algunas piedras y un molino móvil. El resto del relleno de la fosa incluía pequeños fragmentos cerámicos, indicativos de la cercanía de un poblado (Parcero Oubiña 1997; Criado Boado et al. 2000).

Es posible que en Fontela de Figueirido, Castelo de Paiva, hubieran existido estructuras funerarias en fosa, como la número 1, de perfil ovoide y base aplanada, que presentó cerca del fondo un conjunto de cinco piedras y un vaso con decoración de mamelones y restos de fuego. En el lugar se encontraron varias estructuras excavadas en la arcilla, probablemente relacionadas con un poblado (Cunha 1991).

Otras fosas eventualmente tumulares son las de Campo do Postigo/Beiriz, Póvoa do Varzim (A.C.F. Silva 1985). Aquí, en la fosa 2, cubierta por una potente capa de arcilla (Lám. VIII), yacía un vaso con paralelos en otros contextos tumulares regionales como la Mamoa do Carreiro da Quinta, en Vila Verde y en una de las Mamoas
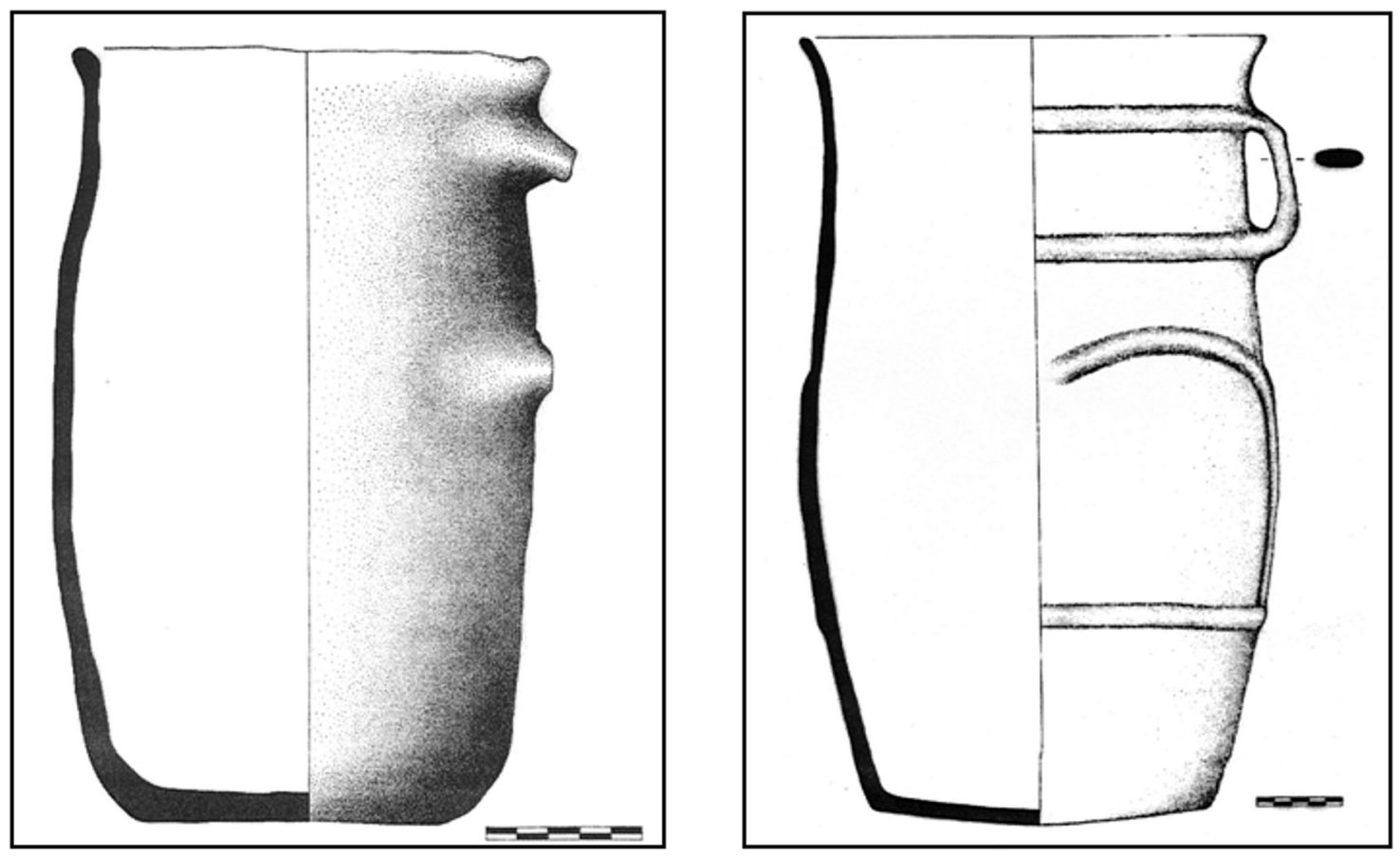

Fig. 6. Dos vasos enteros de las fosas de Boucinhas, Ponte de Lima (según Almeida et al. 1994).

T. P., 67, N. ${ }^{\circ}$ 1, enero-junio 2010, pp. 139-173, ISSN: 0082-5638 doi: $10.3989 /$ tp.2010.10034 


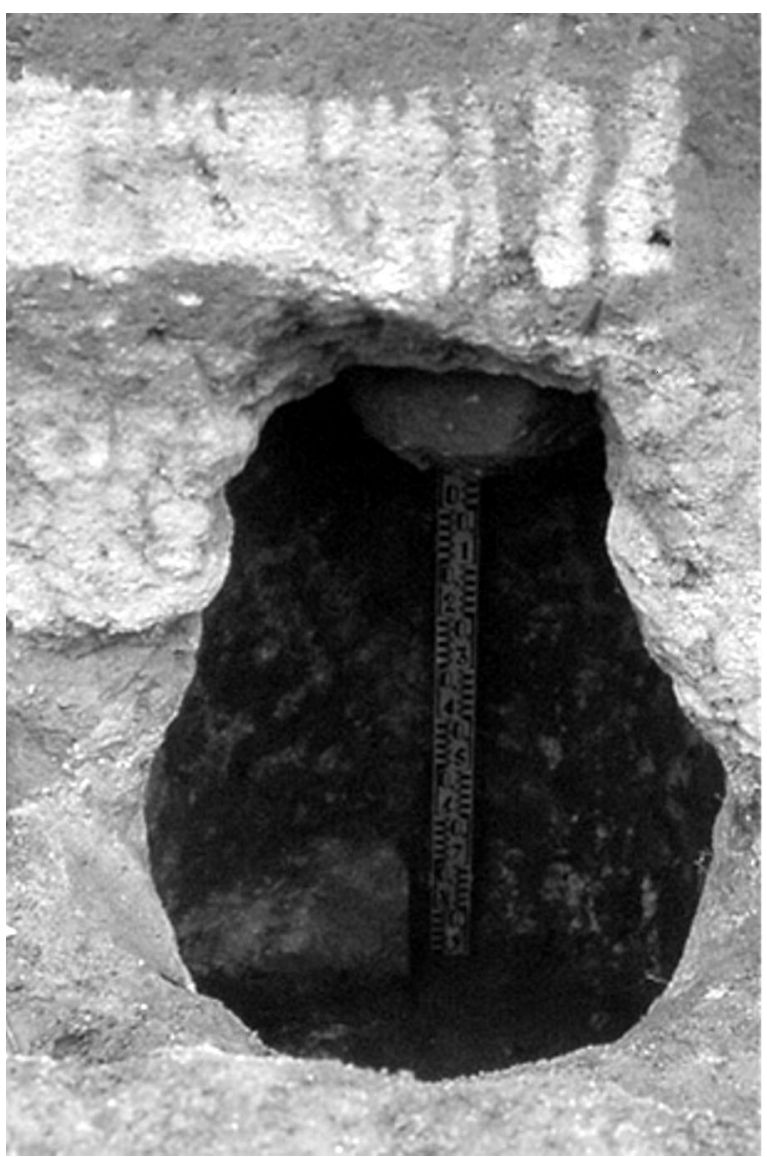

Lám. VIII. Fosa de Campo do Postigo, Beiriz, Póvoa de Varzim (foto Museu Municipal da Póvoa do Varzim).

dos Prados, Arcos de Valdevez. Es más, las adherencias orgánicas de este último vaso permitieron datarlo entre 1736-1501 AC por lo que es probable que esta forma sea un indicador de contextos tumulares del Bronce Medio (Fig. 7).

Del Bronce Medio o Final sería la necrópolis de fosas de Faísca, Guimarães, localizada en una colina del valle del Ave. Allí más de una decena de fosas de perfil semiovoide, aproximadamente de $1,10 \mathrm{~m}$ profundidad y $80 \mathrm{~cm}$ de diámetro, conservaban un vaso de largo borde horizontal, mal cocido y siempre requemado, dispuesto en vertical a 70-80 $\mathrm{cm}$ de profundidad. Se recogieron ocho vasos en ocho fosas distintas, refiriendo Mário Cardoso (1936: 76) que los trabajadores de la cantera partieron muchos otros, lo que le llevó a defender que estaba frente a "una necrópolis de cierta extensión". Además de este material, la aparición de un vaso con cuatro asas y decoración plástica, en forma de cordón "torcido" en el borde, una pequeña

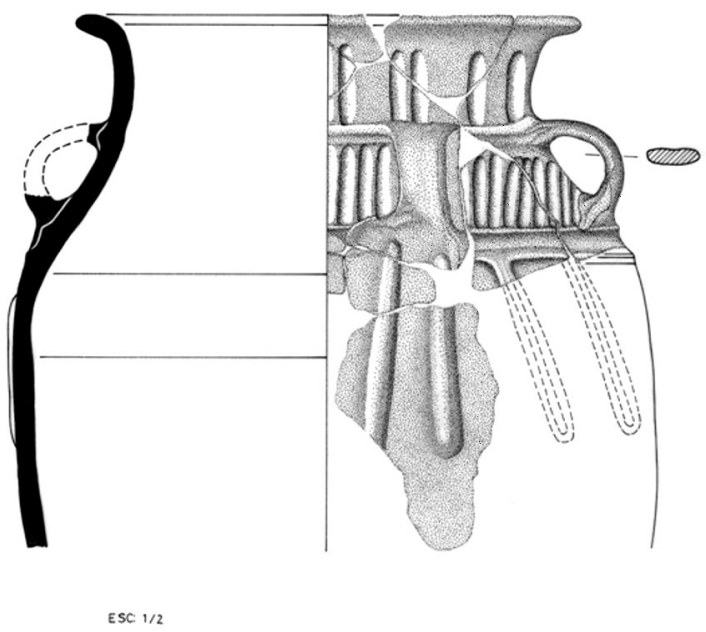

Fig. 7. Vaso presuntamente encontrado en uno de los túmulos megalíticos dos Prados, Arcos de Valdevez (diseño de Dores Pires).

rueda de molino, una piedra discoide pulida en una de las caras y un molino durmiente, cóncavo, podría indicar bien la proximidad de un poblado, bien la existencia de otras estructuras y de los ritos en las que estos objetos se integraban.

Seguramente del Bronce Final son las pequeñas fosas, a veces selladas con arcilla y señaladas con una piedra, existentes en el seno de la necrópolis de sepulturas simples de Pego, en Braga. Dadas sus dimensiones, características, relleno no detrítico y localización, difícilmente podrían ser fosas-silos, por lo que la hipótesis más plausible es que correspondieran a sepulturas o fosas destinadas a ofrendas de carácter funerario-religioso (Sampaio et al. 2008).

Otra fosa de eventual carácter sepulcral sería la detectada en los niveles más superficiales de la necrópolis de Tapado da Caldeira, Baião, que contenía un recipiente cerámico similar a los recuperados en la necrópolis de Paranho, Viseu, datada en el Bronce Final (Vilaça y Cruz 1999). Este lugar parece presentar una larga diacronía en la ocupación, posiblemente de carácter funerario-religioso, en consonancia con la del poblado coetáneo de Bouça do Frade (Cruz y Gonçalves 1998/1999).

Tal vez también sea de carácter sepulcral la fosa cubierta con piedras con un vaso de la forma 15 (urna), localizada al exterior y al Norte de la muralla de la plataforma superior del poblado de S. Julião, Vila Verde, en pleno contexto del Bronce Final (Martins 1988) (Tab. 5). 


\begin{tabular}{|l|l|l|l|l|}
\hline \multicolumn{1}{|c|}{ Fosas } & $\begin{array}{c}\text { Referencia } \\
\text { Laboratorio }\end{array}$ & Fecha BP & 2 sigma cal. & \multicolumn{1}{c|}{ Bibliografía } \\
\hline Cameixa (Boborás) & UtCNr-7276 & $3778 \pm 40$ & $2341-2040$ & Criado Boado et al. 2000 \\
Fraga do Zorro (Verín) & CSIC-1201 & $3438 \pm 43$ & $1882-1638$ & Fábregas 2001; Prieto Martínez et al. 2009b \\
Boucinhas (Ponte de Lima) & AA-63072 & $3739 \pm 50$ & $2294-1980$ & Inédita (Carbón vegetal) \\
\hline
\end{tabular}

Tab. 5. Cronología radiocarbónica de los enterramientos en fosas en el Noroeste de la Península Ibérica (véase nota 3 ).

\subsection{Cuevas y abrigos}

En la zona oriental, donde abundan las formaciones kársticas, principalmente en Asturias, Galicia oriental y Trás-os-Montes las cuevas y los abrigos sirvieron como lugares de enterramiento y de depósito durante toda la Edad del Bronce.

En el territorio portugués destacamos Lorga de Dine, Vinhais, Bragança, con vistas al río Tuela, donde hay indicios de enterramientos (Harpsoe y Ramos 1985) desde, por lo menos, el Calcolítico regional hasta el Bronce Inicial o Medio, evidenciadas por la presencia de un vaso troncocónico y otros carenados. Destacamos, todavía, en el contexto del valle del Angueira y sus afluentes, las cuevas de Ferreiros, Grande y Geraldo, Miranda do Douro (Delgado 1887; Sanches 1992). En esta última habrían aparecido huesos humanos, un hacha plana y un puñal triangular en cobre, cerámica y hueso indicando enterramientos de los inicios de la Edad del Bronce. Todavía en el valle de Angueira en las Fendas do Monte Pedriço se hallaron huesos de dos esqueletos humanos incompletos, asociados a fragmentos de muelas. Es reseñable que no se conocen poblados coetáneos en las inmediaciones de estas cuevas (Delgado 1887; Sanches 1992).

También en el abrigo granítico de Fragão da Pitorca, Chaves (Armbruster y Parreira 1993), conectado con un eventual poblado hubo enterramientos, probablemente desde el Calcolítico hasta el Bronce Inicial (Bettencourt 2009c). Aquí, junto a huesos humanos, se recuperaron cerámicas lisas y decoradas, así como una espiral de oro y un hacha plana todavía con rebabas de fundición.

En el pequeñísimo Abrigo 2 de Fraga dos Corvos, Macedo de Cavaleiros, se descubrió, dentro de una fosa alargada, un pendiente decorado, un pequeño brazalete, una fíbula de doble resorte, una espátula y un fragmento de cinturón (Senna-Martínez et al. 2006; Senna-Martínez et al. 2007) (Lám. IX) que pueden corresponder a los adornos de un individuo enterrado en el Bronce Final en paralelo con el ajuar de la Roça de Casal do Meio, Sesimbra.

Es igualmente probable que los huesos humanos de un juvenil o subadulto, encontrados en la unidad estratigráfica 1 de la Sala 20 del Buraco da Moura de S. Romão, Seia, asociados a materiales de la Edad del Bronce y en las inmediaciones del poblado del Bronce Final del Cabeço da Moura de S. Romão (Senna-Martínez 1989, 1993; Cardoso et al. 1998:261) indiquen enterramientos o deposiciones secundarias de cadáveres (Tab. 6).

En Galicia, por ahora, apenas se conocen enterramientos en la Cueva de Valdavara 2, Becerreá (Fábregas et al. 2009: 28; Vaseao Rodríguez et al. 2009). En Asturias son relativamente frecuentes durante toda la Edad del Bronce (Arias Cabal y Armendáriz Gutiérrez 1998). El caso mejor documentado es el de la Cueva de Fuentenegroso (Peñamellera Alta/Llanes), aparentemente lejos del poblado coetáneo, donde fue enterrada una joven en decúbito lateral con dos brazaletes de bronce, entre 793-543 AC (Barroso et al. 2007a; Barroso et al. $2007 \mathrm{~b})$.

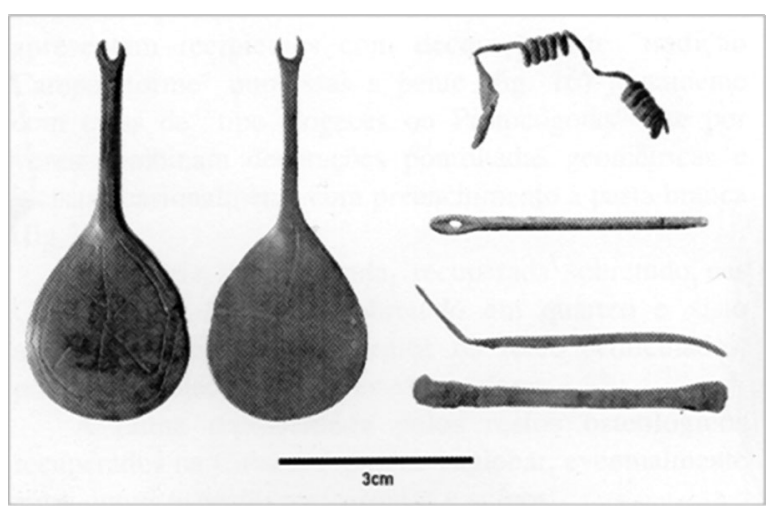

Lám. IX. Objetos de adorno, aguja y espátula del Abrigo 2 de la Fraga dos Corvos, Macedo de Cavaleiros (según Senna-Martinez et al. 2007). 


\begin{tabular}{|c|l|l|l|l|}
\hline Cuevas & $\begin{array}{c}\text { Referencia } \\
\text { Laboratorio }\end{array}$ & \multicolumn{1}{|c|}{ Fecha BP } & 2 sigma cal. & \multicolumn{1}{c|}{ Bibliografía } \\
\hline Fuentenegroso (Peñamellera Alta/Llanes) & Media Pond & $2525 \pm 28$ & $793-543$ & Barroso et al. 2007a, 2007b \\
\hline
\end{tabular}

Tab. 6. Cronología radiocarbónica de enterramientos en cuevas en el Noroeste de la Península Ibérica (véase nota 3).

\subsection{Enterramientos en minas}

Un fenómeno, hasta ahora exclusivo de Asturias durante el Bronce Inicial, son los enterramientos en minas de cobre, como los de El Milagro, Onís y El Aramo, Riosa, donde se recogieron restos de unos 5 y 20 individuos, respectivamente, a veces acompañados de utensilios de minero (Blas 1996, 1998, 2003, 2005).

\subsection{Enterramientos o manipulación de los muertos en estructuras indeterminadas}

Una serie de datos parecen conectarse con prácticas funerarias de la Edad del Bronce, aunque se desconozcan o sean de difícil clasificación las estructuras donde se insertan por la antigüedad de las excavaciones o las vicisitudes de las mismas. Para el Bronce Medio destacamos la estructura funeraria de tipo tumuli, de Guidoiro Areoso, Vila Nueva de Arousa, reutilizada posteriormente a 2131-1886 AC (Alonso y Bello 1997), donde hay vasos de tipo ancho borde horizontal. Para el Bronce Final, recordamos la mitad de un maxilar de adulto, probablemente femenino, encontrada en el Castro de La Campa Torres, Gijón (Mercadal 2001: 889-894) y el depósito de una hoja de hoz en bronce, en la denominada Mamoa da Cova da Moura, Carreço, Viana do Castelo, un monumento de planta oval y gran complejidad constructiva, aparentemente adosado a abrigos naturales, con $48 \mathrm{~m}$ de longitud, $28 \mathrm{~m}$ de anchura y de $8 \mathrm{~m}$ a $11 \mathrm{~m}$ de altura, cuyo tumulus contendría depósitos de cenizas. En el área central existirían varias cavidades en el substrato, aparentemente cubiertas con lajas, algunas de ellas conteniendo cenizas y carbones (Viana 1955).

También en el Bronce Final se podría integrar la estructura de los Granjinhos, Braga, localizada en las inmediaciones del poblado del Alto da $\mathrm{Ci}$ vidade, datable en este período. Consistía en un alineamiento de piedra menuda de contorno inde- finido (12) en cuyo interior se depositaron cuatro vasos enteros en los cuales había materia orgánica con gran contenido en fósforo (Bettencourt 2000c: 223) (Lám. X). Estas características en conjunto posibilitaron su interpretación como estructura funeraria (Bettencourt 1995, 1999, 2000c). Uno de los vasos presentaba un labio en sierra, una característica común a las formas cerámicas del Bronce Final de las cuencas del Lima, Cávado y Ave. No lejos de aquí aparecieron vasos enteros de ancho borde horizontal, aún inéditos, lo que acentúa el eventual carácter funerario de este lugar.

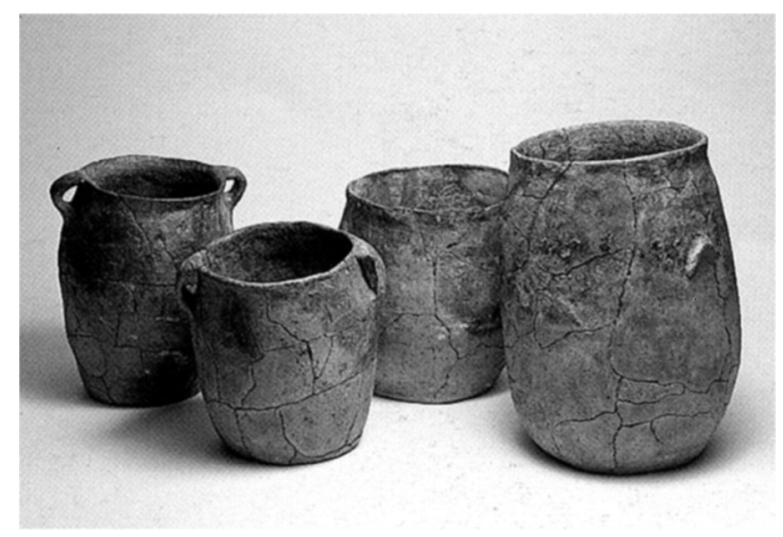

Lám. X. Vasos sepulcrales de los Granjinhos, Braga (foto Museu D. Diogo de Sousa).

\subsection{Otros lugares consagrados a los muertos}

Hay, todavía, otros sitios consagrados a las prácticas funerarias, creados en los inicios de la Edad del Bronce, si no antes. Se caracterizan por una gran diversidad arquitectónica y ritual y por una larga diacronía de utilización y reutilización, a pesar de ser relativamente pequeños y de contar con pocas estructuras de cada período cronológico-cultural, lo que dificulta considerarlos como

(12) Dada la alteración del monumento en época romana 
necrópolis. Generalmente ocupan territorios conectados, directa o indirectamente, con tierras agrícolas.

Uno de estos escenarios asociados al culto a los muertos es la pequeña elevación de Vale Ferreiro, en Fafe, en el final de una espolón de la pendiente sur del río Ave, con amplia visibilidad sobre las áreas circundantes. Bajo ella discurre un río subterráneo de aguas calientes, conocido desde la Edad del Bronce (Bettencourt 2008, 2009a, 2009c, 2010). Aquí, se construyeron dos monumentos de gran inversión pública que parecen materializar la importancia social de este lugar por primera vez. Son los túmulos 1 y 2 . El túmulo 1 (Lám. XI), datado entre 2188-1884 AC, está formado por una pequeña cámara cistoide de tradición megalítica, rodeada por un cairn, compuesto por bloques de cuarzo, totalmente subterrâneo. Fue construido en el interior de una gran fosa cortada en la arcilla, cubierta por una laja granítica y por arcilla lo que permitió preservar el esqueleto de un joven, de unos 15 años (Bettencourt et al. 2002, 2003). El túmulo 2, también subterráneo, con una cámara de mampostería presumiblemente cubierta con madera (Lám. XII), contenía 2 espirales de oro, entre otras ofrendas que podrían datarse en este período (Bettencourt et al. 2005). A pesar de que el sitio no está excavado en su totalidad descubrimos dos sepulturas más, simples y de contorno oval. Una contenía un vasito de tipo Taraio y la otra una ofrenda en material perecedero que yacía sobre un "soporte" compuesto por pequeñas piedras. Excavamos, también, varias fosas de contornos más o menos circulares, de fondo redondeado o aplanado y, a veces, cu-

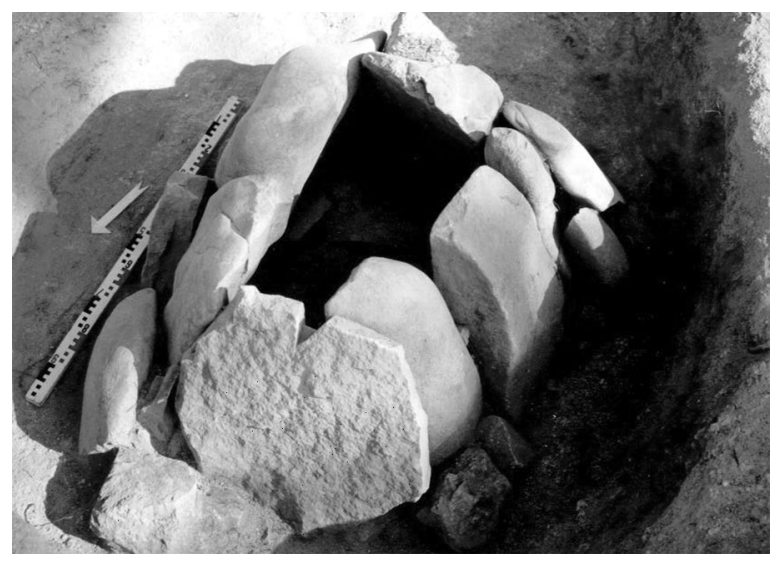

Lám. XI. Sepultura 1 de Vale Ferreiro, Fafe.

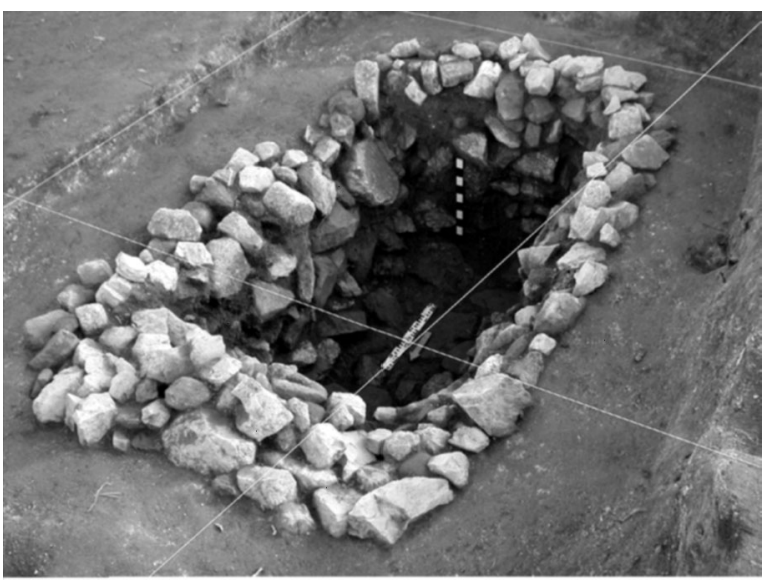

Lám. XII. Sepultura 2 de Vale Ferreiro, Fafe.

biertas con arcilla (Bettencourt et al. 2005). Una de las cuales proporcionó una fecha entre 1738-1466 AC. A menudo estas estructuras están asociadas con uno o dos agujeros de poste (¿postes de señalización?). En el Bronce Final, más precisamente entre 1207-925 AC, situamos una estructura compleja donde una fosa de contorno toscamente oval y rodeada por agujeros de poste terminaba, en la parte más profunda, en una depresión cuadrangular.

Otro lugar que podría tener una significación similar es el de A Devesa de Abaixo, Pontevedra, localizado en una espolón de la vertiente oriental del Monte Faro de Domaio que se destaca topográficamente y que tiene un amplio dominio visual sobre el valle que le queda a la vista. Aquí, desde los inicios de la Edad del Bronce, se construyeron diversas estructuras de enterramiento en fosa y en estructuras líticas atípicas, selladas por arcilla y por una acumulación de piedras conteniendo fragmentos de molinos de unos 35,6 m de longitud y 13,3 $\mathrm{m}$ de anchura, además de una cista, de indicios de variadas acciones ceremoniales y depósitos relacionados con el espacio tumular (Vázquez Liz 2005, Prieto Martínez et al. 2005) (Tab. 7).

Agro de Nogueira, en Coruña, en pleno valle del río Furelos, es otro lugar que tendemos a interpretar genéricamente de este modo, si bien habrá que comprobarlo en el futuro. La primera acción de que tenemos conocimiento en este lugar es una cremación en estructura cistoide, datada entre 2566-2294 AC (Bettencourt y Meijide 2009). Posteriormente se habría construido una sepultura de cámara cistoide, parcialmente ente- 


\begin{tabular}{|c|c|c|c|c|}
\hline Outros contextos & $\begin{array}{c}\text { Referencia } \\
\text { Laboratorio }\end{array}$ & Fecha BP & 2 sigma cal. & Bibliografía \\
\hline Vale Ferreiro 1 (Fafe) & $\mathrm{Ua}-19728$ & $3635 \pm 50$ & 2188-1884 & Bettencourt et al. 2003 \\
\hline Vale Ferreiro (Fafe) (fosa) & Ua -19500 & $3315 \pm 50$ & $1738-1466$ & Bettencourt et al. 2005 \\
\hline Guidoiro/Areoso (V. N. Arousa) & GrN-16108 & $4020 \pm 40$ & 2131-1886 & $\begin{array}{l}\text { Alonso y Bello } 1997 \text { (conchas de } \\
\text { origen marino) }\end{array}$ \\
\hline $\begin{array}{l}\text { Vale Ferreiro (Fafe) (estructura en } \\
\text { fosa con agujeros de poste) }\end{array}$ & AA-63068 & $2875 \pm 41$ & $1207-925$ & Bettencourt et al. 2007 \\
\hline
\end{tabular}

Tab. 7. Cronología radiocarbónica de enterramientos en varios contextos en el Noroeste de la Península Ibérica (véase nota 3).

rrada en una gran fosa circular y cubierta con un amontonamiento de piedras. En su interior yacía un vasito de tipo Taraio lo que indica una cronología del Bronce Inicial. En las inmediaciones de estas dos construcciones, se desenvolvieron toda una serie de estructuras como sepulturas simples de contorno oval o irregular (cubiertas con concentraciones de piedras), fosas de contorno circular y, tal vez, agujeros de poste. Una de las fosas, cuyo interior estaba rellenado con cenizas, fue interpretada como una hoguera relacionada con acciones de carácter funerario o con rituales de cremación (Meijide 1994, 1995, 1996; Fábregas y Meijide 2000).

\section{RESULTADOS E INTERPRETACIÓN}

Este conjunto de datos permite, desde ya, confirmar la existencia de una gran diversidad en las arquitecturas y contextos usados en el ámbito de las prácticas funerario-religiosas, desde el Bronce Inicial hasta el Bronce Final como ya se había admitido desde los años 90 (Bettencourt 1997; Vilaça y Cruz 1999). Se verifica en todos los períodos la reutilización de antiguos monumentos megalíticos, la construcción de pequeños tumuli, de cistas, de estructuras cistoides, de sepulturas simples y de fosas, así como la utilización de espacios naturales, como las cuevas y los abrigos. Sin embargo, gracias al análisis de la distribución geográfica de los diferentes tipos de túmulos y del contexto arqueológico en que se insertan, percibimos tendencias en la distribución espacial de determinadas estructuras $\mathrm{y}$, probablemente, en el modo de vida de las sociedades directamente conectadas con ellas:

- Primero, las necrópolis de cistas, de sepulturas simples y de fosas, o sea, de monumentos simples e invisibles en el paisaje, se establecen en las proximidades de valles con buen potencial para el desarrollo de las prácticas agrícolas, frecuentemente en las inmediaciones o en el interior de poblados. Como sitios en las cercanías de valles destacamos la cista de Quinta de Água Branca y de Lordelo; las necrópolis de cistas de Chedeiro, Atios/Budiño, Agra da Ínsua/Carnota, Cavaleira, Alto da Velha/Gulpilhares, lugar de Belinho, Agra das Antas, Monte da Ola; las necrópolis de sepulturas simples de Cimalha e Pego; las fosas de las Boucinhas, Cameixa, Campo de Postigo, Faísca, entre otras. Próximas a los poblados están bien patentes en Chedeiro y en las Boucinhas y, eventualmente, en Gandón, Cameixa o Fontela de Figueiredo, contextos que creemos del Bronce Inicial. A partir del Bronce Medio este fenómeno se materializa mejor, como se puede comprobar en la necrópolis de Tapado da Caldeira, cercana al poblado de Bouça do Frade, Baião, en la gran necrópolis de Cimalha, Felgueiras, localizada en la periferia del poblado del mismo nombre. Durante el Bronce Final aumentan estos casos. Pensamos en la necrópolis de Pego, en la vertiente sur del poblado y dentro de una empalizada que circunda esta estación; en la cista de $\mathrm{Sr}^{\mathrm{a}}{ }^{\mathrm{a}}$ de Lurdes, en el interior de un recinto murado del poblado del mismo nombre; en la estructura cistoide de Santinha, en el interior de un área delimitada por un murete de contención de tierras, en la vertiente oriental de este poblado y en la fosa cubierta con piedras y conteniendo una urna, externa al talud que circunda la acrópolis de S. Julião;

- Segundo, los monumentos bajo tumuli no megalíticos, con más probabilidad de ser vistos por sus constructores y realizados según una tradición ancestral, se sitúan en áreas amesetadas o montañosas con mayor predisposición para las 
actividades pastoriles, siempre en lugares alejados de los poblados del Bronce Inicial, Medio o Final;

- Tercero, las reutilizaciones de los túmulos megalíticos son comunes a todos los espacios geográficos;

- Cuarto, los enterramientos en cueva y en abrigo son un fenómeno oriental en el contexto del Noroeste Peninsular.

Partimos de la premisa de que el lugar escogido para depositar los muertos, así como el tipo de soluciones arquitectónicas que se les asocian, no son arbitrarios, o condicionados por factores geográficos, sino metáforas de la estructuración social (Hodder 1990) o producciones simbólicas en el sentido de P. Bourdieu 1989 y, por tanto, íntimamente relacionados con los diferentes modos como las comunidades se habrían implicado en el paisaje y lo habrían percibido. Se entiende aquí 'paisaje' como un lugar de experiencias acerca del mundo, un sitio de significaciones en el cual lo sagrado y lo profano, lo simbólico y lo práctico se encuentran intrínsecamente relacionados (Hill 1993).

A partir de ahí parece lícito plantear la hipótesis de que las necrópolis de cistas, de sepulturas simples y de fosas serían materialidades conectadas con comunidades muy implicadas con actividades agrícolas, sedentarias, con un fuerte sentido de la territorialización y con un dominio y conocimiento profundo del territorio. Sólo este tipo de sociedades podrían haber sepultado a sus muertos en estructuras discretas y en lugares difícilmente identificables por otros que no fueran los habitantes locales, en necrópolis, a veces, de dimensiones considerables, en una gran interacción entre la muerte y las restantes áreas de la vida diaria.

Las comunidades más implicadas con paisajes de montaña, eventualmente más dependientes de prácticas pastoriles y con modos de vida que implicarían mayor movilidad, creemos que serían las responsables de la construcción de estructuras funerarias más visibles (monumentos bajo tumuli de tradición megalítica), en una concepción del mundo que parece privilegiar, todavía, la "acotación" de los lugares experimentados a través de la muerte. Tampoco podemos descartar la hipótesis de que, en algunos casos, este tipo de sepulturas resultase de muertes ocurridas en el marco de comunidades con economía mixta que, en época estival, efectuasen desplazamientos estacionales a las áreas montañosas con el ganado comunitario, una práctica típica del Noroeste de la Península Ibérica hasta los inicios del siglo XX. Ello podría explicar la ausencia de poblados, naturalmente situados en cotas más bajas. Una particularidad de estos tumuli es aparecer, a veces, relativamente aislados o el hecho de que, cuando se agrupan, exhiban una diacronía en la ocupación de varios siglos, quizá anunciando sitios tradicionalmente recorridos por muchas generaciones de pastores. El tipo de construcción usado podría estar relacionado con varios factores como, por ejemplo, la necesidad de marcar el lugar de los muertos en territorios donde las fronteras son fluidas, volviéndose memoriales, o con la necesidad de crear arquitectónicas mnemónicas en relación con los monumentos megalíticos, como forma de integrar mentalmente los espíritus de los antepasados.

Tal vez por esta razón se habrían ubicado en lugares a veces impresionantes y con amplio dominio visual (Vilaça y Cruz 1999), factores que contribuyeron a que D. Cruz y R. Vilaça (1999) los considerasen como marcadores de espacios sagrados o de reunión de pueblos vecinos.

En los casos en que las comunidades parecen haber tenido un tipo de vida muy dependiente de la explotación minera se verifica la existencia de enterramientos intencionales en el interior de las propias minas, como en El Aramo y El Milagro, en Asturias, tal vez indicando el papel del cuerpo como ofrenda en lugares impregnados de gran carga mítica, pero simultáneamente utilizados para extraer mineral de cobre como subrayó Miguel Ángel de Blas Cortina (2003, 2005). Tal fenómeno parece evidenciar, una vez más, la ausencia de separación entre los mundos dichos "domésticos", "profanos" y "sagrados".

La reutilización de monumentos megalíticos, durante toda la Edad del Bronce, podría relacionarse con la importancia ideológica del control del pasado y de la historia de los personajes míticos, poniéndolos al servicio de los nuevos órdenes ideológicos y sociales en la perspectiva de $\mathrm{P}$. Bourdieu (1989) y en la perspectiva de que the remaking of the past in the past was both a creative act and an interpretation (Bradley 2003: 226).

No es exclusiva de estas regiones la utilización de cuevas y abrigos, naturalmente, ligada a la disponibilidad de este tipo de espacios subterráneos. A veces, aparecen con otros contextos funerarios, como en Macedo de Cavaleiros donde, además de numerosos abrigos, hay una ne- 


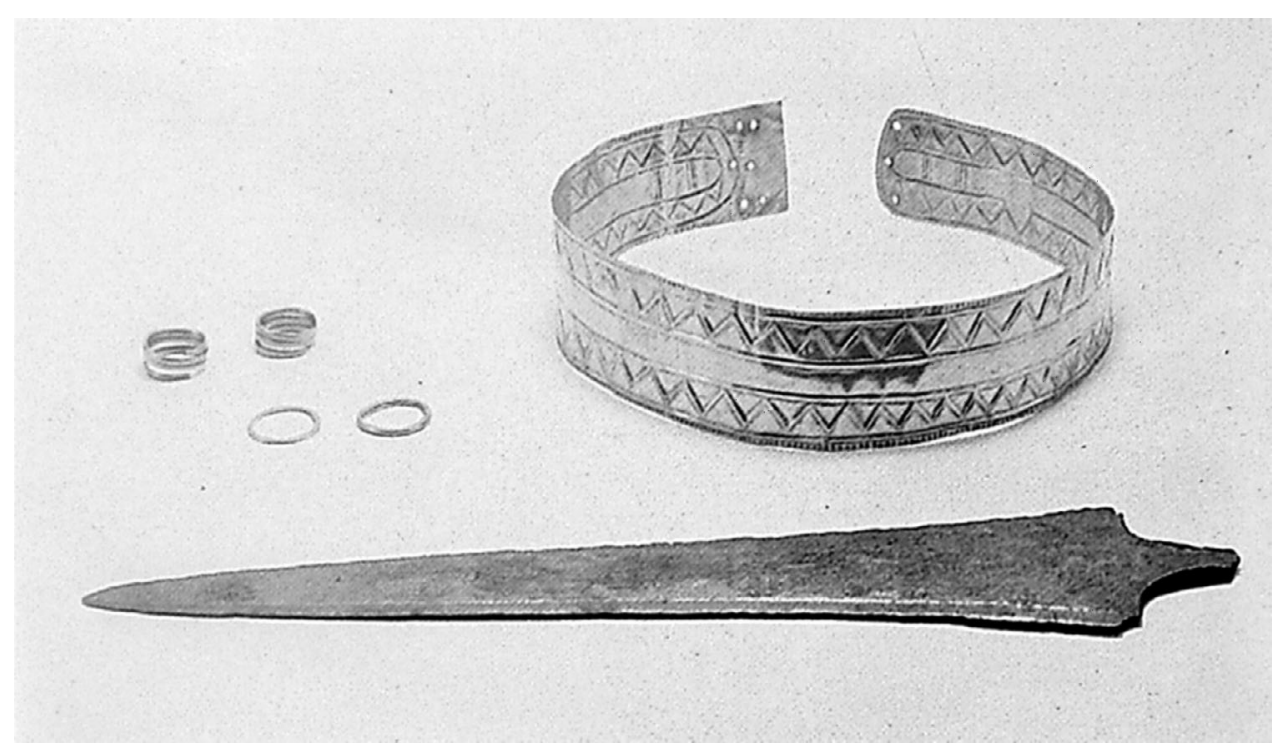

Lám. XIII. Ajuar de la cista da Quinta de Água Branca, Vila Nova de Cerveira (según Cordeiro et al. 1995).

crópolis de cistas. Así el uso de estos espacios naturales tendrá que interpretarse por su propia importancia simbólica o por la del monte, sierra o valle donde se implanta el enterramiento. Tal podría ser la situación de los depósitos de huesos o de los enterramientos en las diferentes cavidades del valle do Angeira o del enterramiento aislado de la cueva de Fuentenegroso, ambos casos lejos de cualquier poblado coetáneo.

Pensando el cuerpo como una materialidad (Sofaer 2006; Fahlander y Oestigaard 2008), otro aspecto que procuramos interpretar fue el del papel social que los vivos habrían conferido a los cadáveres, durante la Edad del Bronce. Para ello analizamos los variados tipos de ofrendas y de adornos que acompañaron a los muertos ya en términos micro-espaciales, ya de su frecuencia o ausencia en términos diacrónicos, teniendo en cuenta, igualmente, el tipo de tratamiento dado al cadáver.

A partir de la base empírica aislamos las siguientes tendencias:

- durante el Bronce Inicial se enterraron algunos cuerpos con ofrendas o adornos de excepción y de grande valor social (Lám. XIII), siempre en estructuras que exigían alguna inversión constructiva, como cistas, pequeños tumuli o monumentos megalíticos, proveyéndose a los restantes cadáveres de las necrópolis de dádivas más modestas;
- durante el Bronce Medio desaparecen los adornos de gran valor social siendo la norma la escasez o ausencia de ajuar junto a los cadáveres (Bettencourt 2005c);

- en los contextos del Bronce Final se mantiene lo que se ha descrito o los enterramientos no se acompañan de depósitos. Estos últimos pueden materializarse mediante recipientes cerámicos tradicionales, como los vasos de ancho borde horizontal (Lám. XIV) o mediante un nuevo repertorio artefactual, como las tazas carenadas, las urnas, algunas formas de ollas (13), las pesas de telar sobre cantos rodados, fusayolas, etc., también manipulado en los contextos residenciales. En este período todavía hay algunos enterramientos excepcionales con adornos en bronce.

En Paranho (Vilaça y Cruz 1999) y, muy probablemente, en los Granjinhos (Bettencourt 1995, 1999, 2000c) se verificó que los vasos sólo parecen servir como receptáculo de las incineraciones en ciertos contextos.

En el tratamiento dado al cuerpo destacamos:

- la preponderancia de la práctica de la inhumación en diferentes contextos del Bronce Inicial y Medio. Se detectaron cadáveres en decúbito dorsal en las cistas de Quinta da Água Branca y en

(13) Según la tabla de formas que establecimos para la Edad del Bronce de la cuenca del río Cávado (Bettencourt 1999, 2000c). 


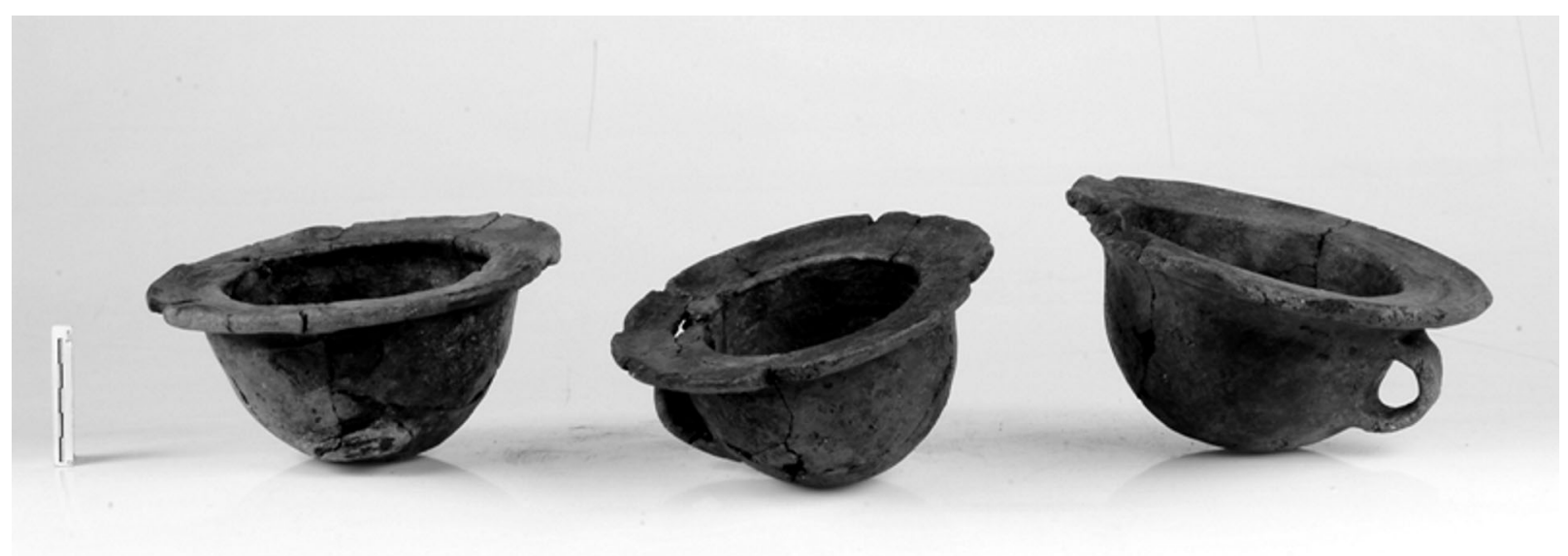

Lám. XIV. Vasos de ancho bordo horizontal de la necrópolis del Pego, Braga (según Sampaio et al. 2008).

Agra de Antas; en decúbito lateral en las minas de El Milagro y El Aramo y de cócoras, en la tumba 1 de Vale Ferreiro. Las dimensiones considerables de muchas cistas y sepulturas simples, de estos períodos, indican igualmente esta práctica;

- el mantenimiento del ritual de inhumación hasta finalizar el Bronce Final, tal como nos indican las dimensiones y características estratigráficas de las sepulturas simples de la necrópolis del Pego y del enterramiento de Fuentenegroso. Tal práctica se desprende, igualmente, de las dimensiones de las cistas de Curvos;

- la práctica de la manipulación de partes del cuerpo físico, en lugares excepcionales, como en Chao Samartín (Villa y Cabo 2003; Villa 2005) y, probablemente, en el poblado de La Campa Torres (Mercadal 2001) en contextos del Bronce Final;

- a pesar de que conocemos incineraciones desde el Calcolítico, como se puede comprobar por la datación de los restos incinerados de la estructura cistoide de Agro de Nogueira (Bettencourt y Meijide 2009), todavía ignoramos la amplitud y significado de esta práctica durante el Bronce Inicial y Medio del Noroeste, dado que las incineraciones de la estructura cistoide de Gandón, Cangas de Morrazo y de una de las cistas de la necrópolis de la Praia da Rola, Muiños (Bettencourt 2009c), no fueron datadas radiométricamente, y los indicios de cenizas y de carbones, en varios monumentos bajo tumuli de la Beira Alta apenas permiten admitir la importancia de los ritos de fuego en el contexto del mundo sepulcral de estos períodos (Cruz y Vilaça 1999). Pero, también sobre la cista de inhumación de la Quinta de Água Branca y en el área contigua existieron ritos de fuego como se desprende de las descripciones efectuadas por J. Fortes (1906). Si, en el Bronce Final, parece verificarse el aumento de las incineraciones en la Beira Alta y en el Minho, en distintos contextos arquitectónicos, como dolmenes (Rapadoro 1) y pequeñas cistas (Paranho), entre otras arquitecturas de difícil interpretación (Granjinhos), teniendo en cuenta la base empírica, todavía no es posible admitir la generalización de esta práctica por el Norte de Portugal o por todo el Noroeste de la Península Ibérica, como se ha defendido (Bettencourt 1995; Barroso et al. 2007b). Lo que podemos afirmar es que, en un análisis a gran escala, los ritos de incineración coexisten con los de inhumación, lo que podrá resultar de procesos de cambio dentro de la continuidad.

La intersección de estos datos nos permite plantear la hipótesis de la existencia de concepciones ideológicas distintas sobre el papel social del cadáver durante la Edad del Bronce. Así, presumimos que durante el Bronce Inicial algunos cadáveres (los portadores de artefactos de excepción) habrían sido manipulados como materialidades para que, en el plano simbólico y social, funcionasen como legitimadores de la posesión de los nuevos territorios ocupados, sea en los valles sea en los montes, y contribuyesen a la construcción y al mantenimiento del nuevo orden ideológico y social de ahí resultante, así como del modo de vida desarrollado. Tal vez estos personajes se hayan transformado en los nuevos ancestros, pudiendo funcionar así a través de diferentes procesos de transmisión de la memoria, como símbolos de mantenimiento de una determinada 
identidad grupal, en un lugar dado. Desde esta perspectiva sugerimos que los objetos extraordinarios que acompañaban estos cuerpos sólo fuesen formas de representación de un cierto poder simbólico, materializado en estos nuevos ancestros y en los agentes que los manipulaban y los mantenían activos en la memoria colectiva (Bettencourt 2008, 2009a, 2009c, 2010). Tal asunción nos aleja de las concepciones en las que, en el marco de la arqueología procesual, se han interpretado estas sepulturas como correspondientes a príncipes, jefes o altos dignatarios, en el ámbito de sociedades muy jerarquizadas. Nuestra hipótesis parece ganar consistencia cuando observamos que, durante el Bronce Medio, tales artefactos/ ofrendas de gran valor comunitario desaparecen de las sepulturas. Ello revelaría, al menos en el plano simbólico, poca distinción social o una aparente igualdad social entre los muertos en una forma de estar en el mundo en la que los cuerpos en cuanto cadáveres perderían su importancia como referentes de la memoria social (Bradley 2000). Pensamos que tal hecho se relaciona, probablemente, con la nueva estructuración de las comunidades y con la consolidación de los procesos de territorialización de las tierras anteriormente ocupadas, situación que se apoya en la restante base empírica del II milenio AC (Ramil Rego 1993; Ramil Rego et al. 1996a, 1996b; Bettencourt 1999, 2000a, 2000b, 2003; 2009a; Bettencourt et al. 2007; Bettencourt y Fonseca 2009). Es posible admitir una situación en que, legitimada la posesión de los nuevos territorios ocupados en el Bronce Inicial, a partir del Bronce Medio la filiación en las comunidades ya no se establecería con respecto a un determinado ancestro, jugando el cadáver un papel sólo en el caso de la descendencia de un linaje individual. Esta situación se habría potenciado durante el Bronce Final, cuando el sitio de enterramiento ya nunca traduciría un escenario público de negociación de la identidad social sino sólo lugares donde se afirmarían las relaciones de parentesco y los lazos familiares. Tal presupuesto podría justificar, por ejemplo, la mayor invisibilidad de las estructuras funerarias, su mayor aproximación a los poblados y la menor especialización de los recipientes cerámicos asociados a las prácticas funerarias. Tales características, bien patentes en el Bronce Final de las tierras bajas, parecen argumentar en favor de la hipótesis de que los actos relacionados con la muerte se interrelacionaban, cada vez más, con otras acciones de la vida diaria.

Pero si, de una forma general, el cadáver parece perder importancia como materialidad usada para promover la identidad social y como legitimador de la ocupación de un territorio, el mantenimiento del cuerpo físico o de partes del mismo hasta terminar el Bronce Final, indica la persistencia, por lo menos en algunos lugares, de una visión cosmológica en la que este es todavía esencial y manipulable en acciones de carácter colectivo. Así se ha interpretado la manipulación de partes del cuerpo y su depósito posterior en otros contextos, como la bóveda craneana detectada en la entrada del recinto de Chao Samartín y la mandíbula de Campa Torres, consideradas reliquias fundacionales (Villa y Cabo 2003; Barroso et al. 2007b) o tal vez de personajes míticos, actuantes como elemento de interconexión, por lo menos en el plano simbólico, entre el mundo de los muertos y el de los vivos. Otras veces el cuerpo podría haber funcionado como "ofrenda" en lugares tradicionalmente "sagrados", como en el enterramiento aislado de Fuentenegroso, donde una joven fue enterrada en una galería recóndita de una cueva en la sierra de Cuera, en la que hay enterramientos desde el Mesolítico (Barroso et al. 2007a).

El discurso de la muerte, por sí solo, no permite más que una percepción truncada del pasado. Debe ser interpretado en su contexto social, inferido, a partir de la totalidad de la base empírica sobre la Edad del Bronce (Bettencourt 1999, 2000a, 2000b, 2000c, 2000d, 2001, 2003, 2005a, 2005b, 2005c, 2007, 2008, 2009a; Bettencourt et al. 2007; Bettencourt y Fonseca 2009; Caamaño Gesto 2007; Canha 2002; Comendador Rey 1997, 2001; Cruz et al. 2000; Jorge 1988, 1991, 1999; Jorge y Jorge 2006a, 2006b; López Sáez y Cruz 2002/2003; López Sáez et al. 2000; Loureiro 2003; Martins 1990; Senna-Martínez 2000a, 2000b; Suárez Otero 2002, Valinho 2003, entre otros). Según este análisis más global, en el Bronce Inicial la legitimación simbólica de la ocupación del territorio y la aparición de un nuevo poder parece ser un fenómeno generalizado, al hacerse, no sólo en las tierras marcadas por los ancestros sino en las nuevas.

En el primer caso, ello se materializaría a través de acciones relacionadas con la deposición de algunos cadáveres en los antiguos templos-túmulos megalíticos y en la construcción de nuevas estructuras funerarias en sus inmediaciones, como ya vi- 
mos anteriormente, pero también, a través de las primeras estelas grabadas con simbología metálica (Lám. XV) y de la reinterpretación de algunos espacios de "arte rupestre". Allí se graban ahora puñales y alabardas, explicados como una forma simultánea de individualización y de perpetuación de las imágenes tradicionales de los ancestros por parte de los nuevos actores del poder (Bueno Ramírez et al. 2005; Bueno y Balbín 2006).

Tampoco se excluyen acciones que implicaran la reocupación de otros lugares naturales previamente utilizados, como la sierra de Cuera donde se realizaron diversas inhumaciones en cuevas o abrigos, desde el Mesolítico (Barroso Bermejo et al. 2007) o el valle de Angeiras donde hay varias cuevas sepulcrales desde, por lo menos el Calcolítico (Bettencourt 2009c). Todavía cabe señalar la frecuentación de antiguos recintos monumentales, como el de Castelo Velho de Freixo de

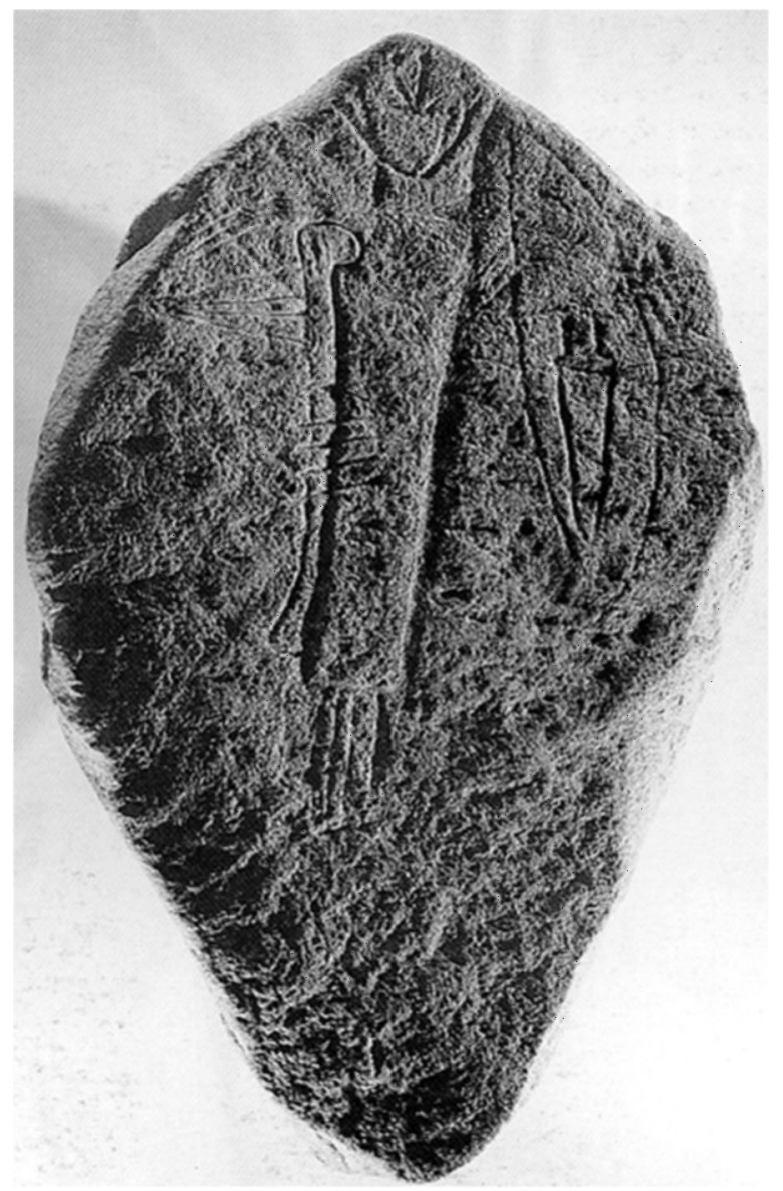

Lám. XV. Estela de Longroiva, Meda (según Cordeiro et al. 1995).
Numão, Vila Nova de Foz Côa (Jorge 2006) o el de Forca, Barca, Maia (Bettencourt 2009b).

La legitimación de la ocupación de las nuevas tierras parece efectuarse a través de algunos cadáveres acompañados de artefactos de gran valor simbólico y social, depositados en las necrópolis correspondientes a la nueva red de poblamiento; en el depósito de cadáveres en las minas de cobre de El Aramo y El Milagro; en la construcción ex-nihilo de nuevos sitios destinados al culto de algunos muertos que serán manipulados a través de procesos de transmisión de la memoria y se mantendrán activos en la larga duración, como parece ser el caso de Vale Ferreiro (Bettencourt et al. 2005; Bettencourt 2008, 2009a); en el grabado o depósito de nuevos símbolos de poder - las "armas" metálicas en cobre - en nuevos lugares naturales, como en la fachada más litoral del Noroeste de la Península Ibérica y en la más oriental, respectivamente.

A partir del Bronce Medio los escenarios de negociación del poder y de la identidad social parecen trasladarse a otros contextos de acción distintos de las prácticas funerarias. Se sabe que durante este período se intensifican las prácticas agro-silvo-pastoriles bien patentes en las alteraciones de la cubierta vegetal y en la aparición de poblados de grandes dimensiones y se introduce la metalurgia del bronce lo que implica la explotación y la circulación de estaño, uno de los recursos abundantes en el Noroeste, así como la fabricación de piezas y su manipulación. De este modo creemos que las acciones y los escenarios de poder se van transfiriendo a la esfera de los vivos, como por ejemplo a donde se explota el estaño, como podría indicar el depósito de un hacha de tipo Bujões/Barcelos en la mina de la Folgadoura, Viana do Castelo; a los lugares de fabricación, manipulación y deposición de artefactos en bronce, estos últimos bien patentes en diferentes espacios naturales relacionados con las aguas, con los afloramientos y con el propio subsuelo (Bettencourt 1999; 2005c; 2009a); a la edificación de una estatuaria de grandes dimensiones donde se graban nuevas armas y nuevos símbolos de poder y a los escenarios donde éstas se erigen $\mathrm{y}$, por último, pero no menos importante, al interior de los mismos poblados, cada vez mayores y más impresionantes en el paisaje (Bettencourt 2009a). Esta variedad de escenarios y de acciones, algo distintas de las del período anterior, indican comunidades que viven y perciben, en tér- 


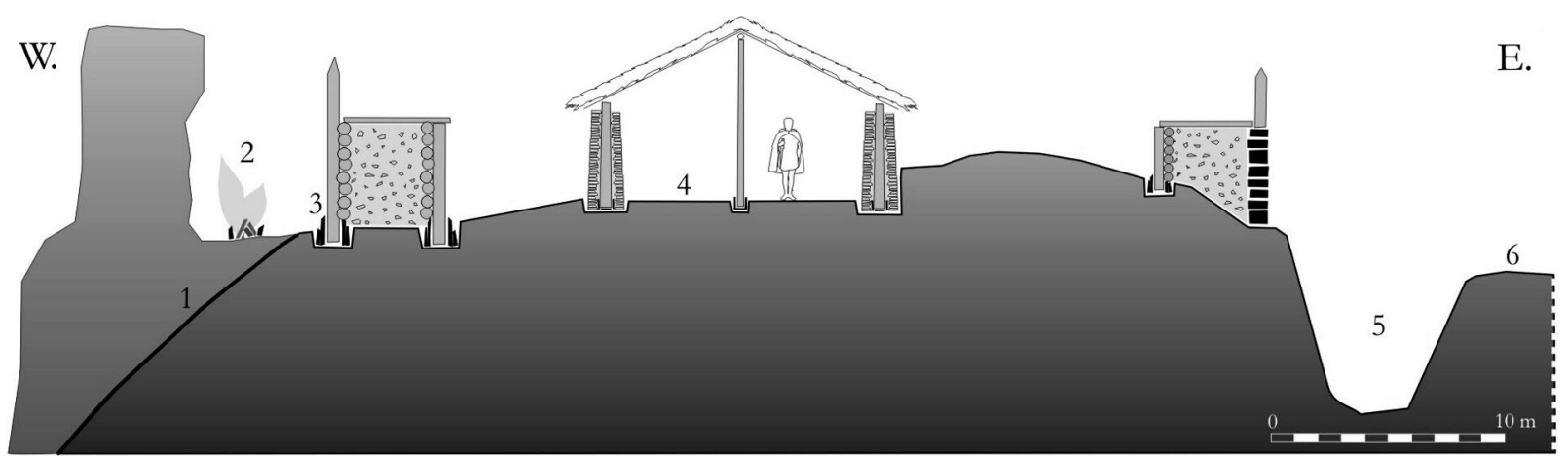

Fig. 8. Estructuras de la acrópolis de Chao Sanmartín, Grandas de Salima (según Villa y Cabo 2003).

minos simbólicos, un nuevo modo de estar en el mundo más sedentario, más antropizado, más basado en las prácticas agrícolas de base cerealista y en la actividad pastoril a gran escala, así como en la explotación de nuevos terrenos relacionados con la extracción de estaño, materia prima ciertamente cargada de propiedades particulares (Bettencourt 1999; 2000a; 2003; Bettencourt et al. 2007; 2009a; Bettencourt y Fonseca 2009).

En el Bronce Final la eventual pérdida de importancia del cadáver físico, sobre todo en los lugares o períodos en que los indicios de incineración parecen ser más usuales, nos permite presumir que las materializaciones de las acciones de negociación del poder y de promoción de la identidad grupal deben continuar obteniéndose en una multiplicidad de lugares y de actos, en una lógica que se inicia en el período anterior. Tal vez el poder se materialice, de forma más intensiva, en la extracción y en los actos que culminan en la deposición de metal en lugares naturales, que au-

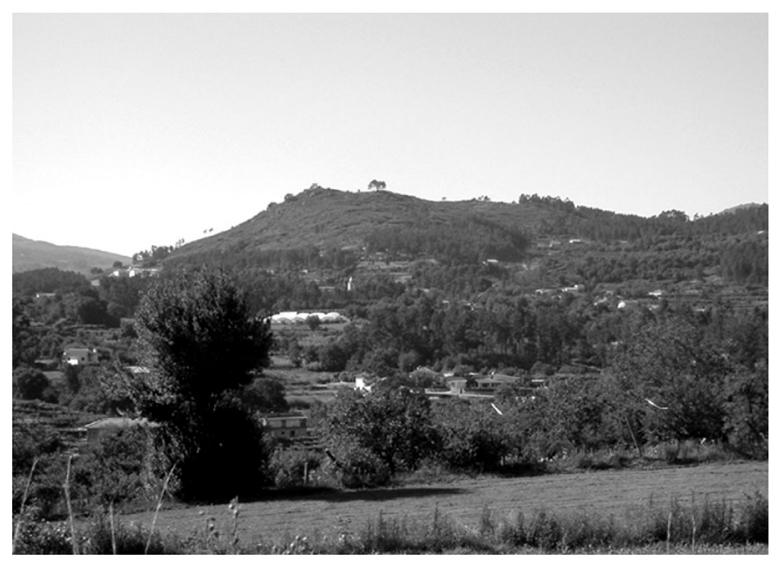

Lám. XVI. Localización de S. Julião, Vila Verde. mentarán considerablemente en el Bronce Final; en los diversos tipos de poblados donde éste se fabrica y manipula a pequeña escala; pero también y cada vez más, en el interior de aquellos emplazamientos en altura verdaderamente excepcionales, a veces con murallas, y donde las acciones implican la manipulación de varios y diversificados artefactos metálicos, entre otros de materias primas excepcionales, $y$, algunas veces de gran cantidad de recipientes cerámicos extraordinarios (2009a). Nos referimos, por ejemplo, a los recintos de Chao Samartín, Grandas de Salime, en Asturias (Villa y Cabo 2003; Villa 2005) (Fig. 8), a S. Julião, Vila Verde (Lám. XVI) y al Alto da Pena, Ponte de Lima, ambos en el Minho (Bettencourt 2005a, 2009a), Cividade, Arouca, na Beira Litoral (A. Silva y Leite 2010) a Sr. ${ }^{\text {a }}$ da Guia/Baiões, S. Pedro do Sul (Kalb 1995) (Lám. XVII) y quizás Vila Cova-à-Coelheira, Vila Nova de Paiva (Loureiro 2003), ambos en la Beira Alta, cuya localización y arquitecturas excepcionales, por sí solas, expresan "dominio y superioridad" en términos del entorno. En esta lógica, también es probable que se intensifiquen las estatuas-menhires del Noroeste, durante el Bronce Final (14), actuantes como agentes sociales

(14) A pesar de la tendencia reciente a fechar las estatuas-menhires del Noroeste de la Península Ibérica, provistas de un símbolo de forma trapezoidal, en cronologías antiguas, creemos que la mayoría de ellas deben asignarse al Bronce Medio y al Bronce Final, ya sea porque las historias o relatos relacionados con los seres humanos son transferidos principalmente a las esferas de la vida, durante estos períodos, ya sea porque existen paralelos en bronce para los colgantes de extremo distal en trompeta representados en la estatua-menhir de São João de Ver, Portugal. Estos aparecen en los niveles arqueológicos I y II del Castro de Torroso, Mós, Pontevedra, con tres fechas de radiocarbono entre 800 y 540 AC (Peña Santos 1992), es decir en la Edad del Bronce Final o a principios de la Edad del Hierro regional, según el autor. 


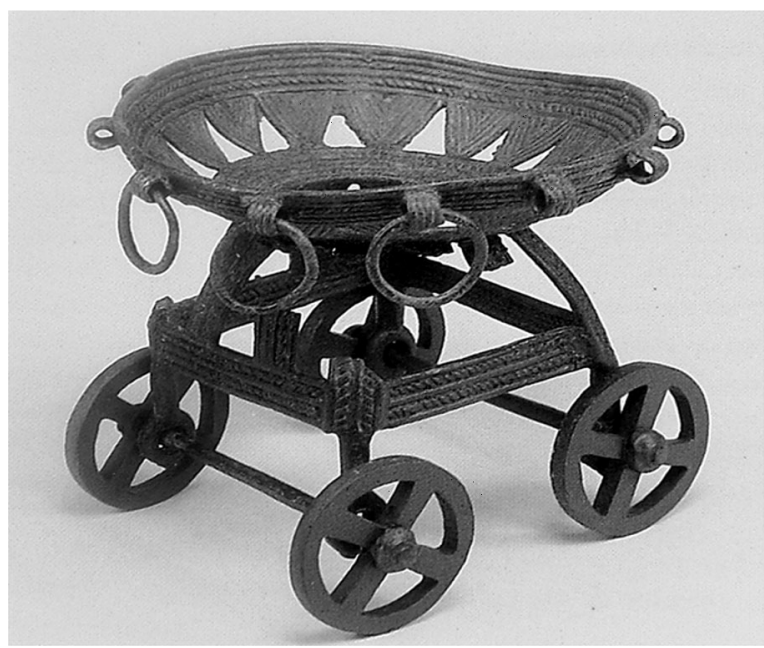

Lám. XVII. Artefacto votivo de Sr. ${ }^{a}$ da Guia, Baiões, S. Pedro do Sul (según Alarcão y Santos 2007).

donde toma cuerpo la memoria del poder de algunos actores o de personajes míticos (Bettencourt 2008, 2009a, 2010) cuyas "historias" se recuerdan a través de los símbolos allí grabados (Fig. 9). Hipótesis similar fue defendida por R.J. Harrison (2004) para explicar las estelas del Bronce Final del suroeste de la Península Ibérica. En esta lógica de la ocupación e interacción con el territorio y de la pérdida de importancia de los muertos como agentes de agregación social no tiene sentido pensar que las estatuas del Noroeste tuvieran un carácter extrictamente funerario, como varios autores han sostenido. Habría que
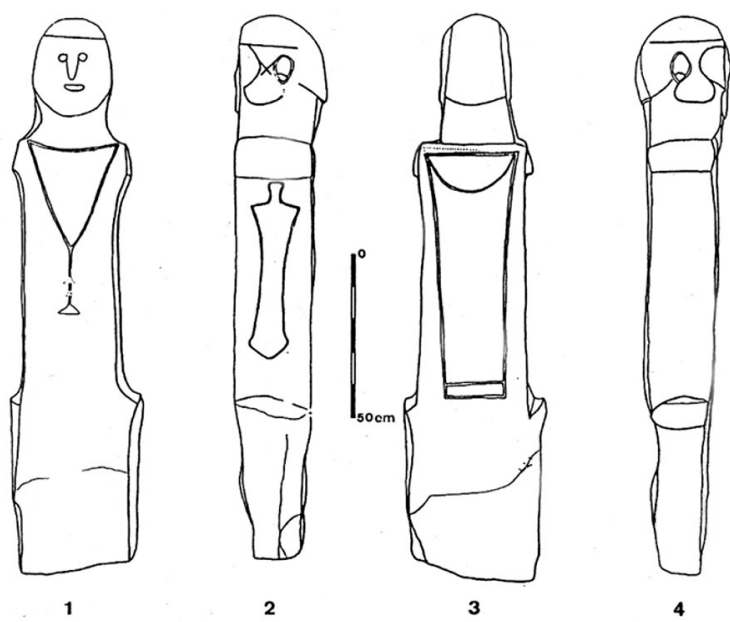

Fig. 9. Estatua-menhir de S. João de Ver, Arouca (según V.O. Jorge y S.O. Jorge 1990). interpretarlas, más bien, como el elemento visible de los lugares públicos y de reunión. Esto podría explicar el hecho de que estén vinculadas a las rutas de tránsito, como se ha defendido hace tiempo (Bettencourt 1995, S. Jorge 1999a, etc.) y de que se iergan, a menudo en espacios abiertos. De cualquier modo es posible que, en algunas localidades del Noroeste, "todo vuelva al principio" y que, de nuevo, en el Bronce Final, algunos cadáveres ganen protagonismo como entidades sociales portando adornos en bronce, pero ello sólo podrá comprenderse en la lógica de las contingencias.

En suma, si cabe admitir que la investigación de estos últimos años permitió un conocimiento considerable sobre la muerte durante la Edad del Bronce del Noroeste de la Península Ibérica, también es verdad que nuestras interpretaciones privilegian aún una amplia escala de análisis siendo, por tanto, reductoras en términos de los particularismos que parecen prefigurarse, debiendo, por eso, abordarse como punto de partida para estudios de carácter más local dentro de una perspectiva necesariamente holística.

\section{AGRADECIMIENTOS}

A M. ${ }^{a}$ Isabel Martínez Navarrete (Grupo de investigación Prehistoria social y económica, Instituto de Historia, Centro de Ciencias Humanas y Sociales - CSIC) por la dedicación que ha demostrado en la traducción de este texto al castellano, a los revisores por su asesoramiento y a los colegas que nos facilitaron información inédita.

\section{BIBLIOGRAFÍA}

Aboal Fernández, R.; Ayán Vila, J.; Criado Boado, F.; Prieto Martínez, M.P. y Tabarés Domínguez, M. 2005: "Yacimientos sin estratigrafia: Devesa do Rei, un sítio cultual de la prehistoria reciente y la protohistoria de Galicia?". Trabajos de Prehistoria 62 (2): $165-180$.

Alarcão, J. y Santos, A.I.P. (coord.) 1997: De Ulisses a Viriato. O primeiro milénio a.C. Museu Nacional de Arqueologia. Lisboa.

Almeida, C.A.B. 1986: "Carta arqueológica do concelho de Esposende". Boletim Cultural de Esposende 9/10: 39-59. 
Almeida, C.A.B. 1989: "Carta arqueológica do concelho de Esposende". Boletim Cultural de Esposende 15/16: 90-101.

Almeida, C.A.B.; Almeida, P.B. y Francisco, F. 2008: Povoado do Bronze Final da Cimalha. Sernande, Felgueiras. Relatório de Intervenção Arqueológi$c a$. Câmara Municipal de Felgueiras. Felgueiras.

Almeida, C.A.B.; Maia, M.I.S.; Moreira, M.M.L. y Baptista, A.J. 1994: "A estação do Bronce Final da Regueira. Vitorino de Piães - Ponte de Lima". Revista da Faculdade de Letras. História 2. ${ }^{a}$ serie 11: 547-565.

Almeida, P. B. y Fernandes, F. 2008: "O povoado da Idade do Bronze da Cimalha". Actas do I Encontro de Arqueologia das Terras do Sousa (Lousada, 2007). Oppidum Número Especial: 29-44 PDF.

Alonso, F. y Bello, J.M. ${ }^{a}$ 1997: "Cronología y periodización del fenómeno megalítico en Galicia a la luz de las dataciones por Carbono 14". En A. Rodríguez Casal (coord.): O Neolítico Atlántico e as Orixes do Megalitismo. Universidad de Santiago de Compostela. Santiago de Compostela.

Álvarez Blázquez, J.M.; Acuña Castroviejo, F. y García Martínez, M.C. 1970: "Cista e ajuar funerario de Atios (Porriño)". Cuadernos de Estudios Gallegos 75: 20-36.

Alves, F.M. 1975: Memórias 9. Museu o Abade de Baçal. Bragança.

Arias Cabal, P. y Armendáriz Gutiérrez, A. 1998: "Aproximación a la Edad del Bronce en la región cantábrica”. En R. Fábregas (ed.): A Edad del Bronce en Galicia: nuevas perspectivas. Cadernos do Seminário de Sargadelos 77. Coruña: 47- 80.

Armbruster, B.R. y Parreira, R. 1993: Inventário do Museu Nacional de Arqueologia: Colecção de Ourivesaria. Do Calcolítico à Idade do Bronze. Instituto Português de Museus. Lisboa.

Ataíde, A. y Teixeira, C. 1940: "A necrópole e o esqueleto de S. Paio de Antas e o problema dos vasos de largo borde horizontal". Actas do $1 .{ }^{\circ}$ Congresso do Mundo Português (Lisboa, 1940): 669-692. Lisboa.

Baptista, J.D. 1999: “As cistas de Vila da Ponte". Aquae Flaviae 21: 333-352.

Barret, J. 1994: Fragments from antiquity. Blackwell. Oxford.

Barret, J. 2001: "Agency, the duality of structure, and the problem of the archaeological record". En I. Hodder (ed.): Archaeological Theory Today. Polity Press. Cambridge: 141-164.

Barroso Bermejo, R.; Bueno Ramírez, P.; Camino Mayor, J. y Balbín Behrmann, R. 2007b: "Fuentenegroso (Asturias), un enterramiento del Bronce Final - Hierro en el marco de las comunidades atlánticas peninsulares". Pyrenae 38 (2): 7-32.

Barroso Bermejo, R; Camino Mayor, J.; Bueno Ramírez, P. y Balbín Behrmann, R. 2007a: Fuentenegro- so. Un enterramiento del I milenio A.C. en la sierra de Cuera, Asturias. Consejería de Cultura Comunicación Social y Turismo. KRK ediciones Oviedo.

Bettencourt, A.M.S. 1982: "A propósito de um vaso tronco-cónico do Museu de Aveiro". Arqueologia 5: 40-43.

Bettencourt, A.M.S. 1988: "Os vasos tronco-cónicos da estação arqueológica do Castêlo - Sever do Vouga". Arqueologia 18: 99-104.

Bettencourt, A.M.S. 1995: "Dos inicios aos finais da Idade do Bronze no Norte de Portugal". En Isabel Cordeiro, I. Silva y M.A. Fernandes (coord.): $A$ Idade do Bronze em Portugal. Discursos do Poder. Instituto Portugués de Museus. Lisboa: 110-115.

Bettencourt, A.M.S. 1997: "Expressões funerárias da Idade do Bronze no Noroeste peninsular". En P. Bueno Ramírez y R. de Balbin (coord.): Actas del II Congreso de Arqueología Peninsular (Zamora, 1996): 621-632. Zamora.

Bettencourt, A.M.S. 1999: A Paisagem e o Homem na bacia do Cávado durante o II e I milénios AC. Universidade do Minho. Braga.

Bettencourt, A.M.S. 2000a: “O vale do Cávado (Norte de Portugal) dos finais do III milénio aos meados do I milénio AC: sequências cronológico-culturais". En V.O. Jorge (coord.): Actas do 3. ${ }^{\circ}$ Congresso de Arqueologia Peninsular (Vila Real, 1999) 4, Pré-História Recente da Península Ibérica: 79-93. Porto.

Bettencourt, A.M.S. 2000b: O povoado da Idade do Bronze da Sola, Braga, Norte de Portugal. Cadernos de Arqueologia, Monografias 9, Unidade de Arqueologia da Universidade do Minho. Braga.

Bettencourt, A.M.S. 2000c: Estações da Idade do Bronze e Inícios da Idade do Ferro da bacia do Cávado (Norte de Portugal). Cadernos de Arqueologia, Monografias 11, Unidade de Arqueologia da Universidade do Minho. Braga.

Bettencourt, A.M.S. 2000d: O povoado de S. Julião, Vila Verde, Norte de Portugal, na Idade do Bronze e na Transição para a Idade do Ferro, Cadernos de Arqueologia, Monografias 10, Unidade de Arqueologia da Universidade do Minho. Braga.

Bettencourt, A.M.S. 2001: O povoado da Santinha, Amares, Norte de Portugal, nos finais da Idade do Bronze. Cadernos de Arqueologia, Monografias 12, Unidade de Arqueologia da Universidade do Minho. Braga.

Bettencourt, A.M.S. 2003: "Plant and animal husbandry in the second millennium BC in Northern Portugal”. Journal of Iberian Archaeology 5: 199-202.

Bettencourt, A.M.S. 2005a: "O que aconteceu às populações do Bronze Final do Noroeste de Portugal, no segundo quartel do I milénio AC, e quando começou, afinal, a Idade do Ferro?". Actas do Colóquio Internacional. Castro, um lugar para habitar, 
Penafiel - 2004. Cadernos do Museu 11. Câmara Municipal de Penafiel. Penafiel: 25-40.

Bettencourt, A.M.S. 2005b: “A arquitectura dos recintos monumentais". En J.M. Hidalgo Cuñarro (coord.): Arte e Cultura de Galicia e Norte de Portugal. Arqueoloxía. Nova Galicia Edicións, S.L. Vigo 1: 122-129.

Bettencourt, A.M.S. 2005c: "Obxectos de adorno (ouro, prata e cobre/bronce)". En J.M. Hidalgo Cuñarro (coord.): Arte e Cultura de Galicia e Norte de Portugal. Arqueoloxía. Nova Galicia Edicións, S.L. Vigo 1:187-197.

Bettencourt, A.M.S. 2008: "Life and death in the bronce age of the NW Iberian Peninsula". En F. Fahlander y T. Oestigaard (eds.): The materiality of death - bodies, burials and beliefs. British Archaeological Reports, International Series 1768, Archaeopress. Oxford: 99-104.

Bettencourt, A.M.S. 2009a: "A Pré-História do Minho: do Neolítico à Idade do Bronze". En P. Pereira (coord.): Minho. Traços de Identidade. Conselho Cultural da Universidade do Minho. Braga: 70-113.

Bettencourt, A.M.S. 2009b: "Comunidades pré-históricas da bacia do Leça”. En O Rio da Memória: Arqueologia no Território do Leça. Câmara Municipal de Matosinhos. Matosinhos: 30-81.

Bettencourt, A.M.S. 2009c: "Práticas Funerárias da Idade do Bronze de Trás-os-Montes e da Galiza oriental". Actas do Congresso Transfronteiriço de Arqueologia: um Património sem Fronteiras (Barroso, Montalegre, 2008). Revista Aqvae Flaviae 41: 93-105.

Bettencourt, A.M.S. 2010: "Burials, corpses and offerings in the Bronze Age of NW Iberia as agents of social identity and memory". En A.M.S. Bettencourt, M.J. Sanches, L.B. Alves y R. Fábregas (eds.): Conceptualizing space and place. On the role of agency, memory and identity in the construction of space from the Upper Palaeolithic to the Iron Age in Europe. Proceedings of the $15^{\text {th }}$ Congress of the International Union for Prehistoric and Protohistoric Sciences, Lisbon, September 2006. British Archaeological Reports, International Series 2058. Archaeopress. Oxford: 33-45.

Bettencourt, A.M.S. y Fonseca, J. 2009: O povoado da Idade do Bronze de Lavra, Matosinhos. Contributos para o Estudo do Bronze Médio do Litoral Norte. Câmara Municipal de Matosinhos. Matosinhos.

Bettencourt, A.M.S.; Lemos, F.S. y Araújo, T. 2002: "The young man of Vale Ferreiro Fafe (northern Portugal): an early Prehistorical burial". Journal of Iberian Archaeology 4: 131-151.

Bettencourt, A.M.S.; Lemos, F.S. y Araújo, T. 2003: "O complexo arqueológico de Vale Ferreiro, Serafão, Fafe (Norte de Portugal)". Trabalhos de Antropologia e Etnologia 43 (1-2): 113-132.
Bettencourt, A.M.S. y Meijide Camessele, G. 2009: "Agro de Nogueira, Melide, Lugo: nuevos datos e nuevas problemáticas". Gallaecia 28: 33-40.

Bettencourt, A.M.S.; Dinis, A.; Silva, A.; Veiga, A.M.; Ribeiro, E.; Cardoso, H.; Vilas Boas, L. y Amorim, M.J. 2004: "A estação arqueológica das Boucinhas, Regueira, Vitorino de Piães, Ponte de Lima (Norte de Portugal)". Portugália 25: 87-109.

Bettencourt, A.M.S.; Dinis, A.; Figueiral, I.; Rodrigues, A; Cruz, C.S.; Silva, I.S.; Azevedo, M. y Barbosa, R. 2007: “A ocupação do território e a exploração de recursos durante a Pré-História Recente do Noroeste de Portugal". En S.O. Jorge, A.M.S. Bettencourt y I. Figueiral (eds.): A Concepção das Paisagens e dos Espaços na Arqueologia da Península Ibérica. Actas do $4{ }^{\circ}$ Congresso de Arqueologia Peninsular (Faro, 2004): 149-164. Faro.

Bettencourt, A.M.S.; Rodrigues, A; Silva, I.S.; Cruz, C.S. y Dinis, A. 2005: "The ceremonial site of Vale Ferreiro, Fafe, in the context of the Bronze Age in Northwest Portugal". Journal of Iberian Archaeology. 7: 157-175.

Blas, M.A. 1983: La Prehistoria reciente en Asturias. Fundación Pública de Cuevas y Yacimientos Arqueológicos. Oviedo.

Blas, M.A. 1985: "Piedrafita V. Nuevos aspectos sobre el polimorfismo de las arquitectuas funerárias prehistóricas en el N-NO de la Península Ibérica”. Arqueologia 12: 129-136.

Blas, M.A. 1994: “El anillo áureo de tiras de la Mata'1 Casare I su localización megalítica". Madrider Mitteilungen 35: 107-122.

Blas, M.A. 1996: "La primera minería metálica del N. Peninsular: las indicaciones del C-14 y la cronología prehistórica de las explotaciones del Aramo y el Milagro". Complutum extra 6-I: 217- 266.

Blas, M.A. 1998: "Producción e intercambio de metal: la singularidad de las minas de cobre prehistóricas del Aramo y El Milagro (Asturias)". En G. Delibes (ed.): Minerales y Metales en la Prehistoria Reciente. Algunos Testimonios de su Explotación y Laboreo en la Península Ibérica. Studia Archaeologica 88, Universidad de Valladolid y Fundación Duques de Soria. Valladolid: 71-103.

Blas, M.A. 2003: "La mina como ámbito infraterreno y el cadáver como ofrenda ritual. A propósito de los esqueletos humanos hallados en las explotaciones cupríferas del Aramo". En J. Férnández Manzano y J.I. Herrán Martínez (eds.): Mineros y Fundidores en el Inicio de la Edad de los Metales. El Midi francés y el Norte de la Península Ibérica. Casa España/Fundación Las Médulas. Léon: 32-48.

Blas, M.A. 2004: "Túmulos enigmáticos sin ofrendas: a propósito de Monte Deva V (Gijón) y Berducedo (Allande), en Asturias". Trabajos de Prehistoria 61 (2): 63-83. 
Blas, M.A. 2005: "Un témoignage probant de l'exploitation préhistorique du cuivre dans la Péninsule Ibérique: le complexe minier d'El Aramo (Asturies)". En P. Ambert y J. Vasea (eds.): La première métallurgie en France et dans les pays limitrophes. Société Préhistorique Française - Mémoire 37. Paris: 195-205.

Bourdieu, P. 1989: O poder simbólico. Difel. Lisboa.

Bouza-Brey, F. 1936: "Vaso Tumular de Gendive". Boletín de la Academia Gallega 31 (261): 236-241.

Bóveda, M.J.; Cañizo, J.A. y Vilaseco, I. 1999: "Lugares para grabar, lugares para morrer. Petroglifos e cistas na Edad del Bronce do N.W. da Península Ibérica". Gallaecia 18: 89-101.

Bradley, R. 2000: An archaeology of natural places. Routledge. Londres/Nueva York.

Bradley, R. 2003: "The translation of time". En R.M. Van Dyke y S.E. Alcock (eds.): Archaeologies of Memory. Blackwell. Oxford: 221-227.

Bueno Ramírez, P. y Balbín Behrmann 2006: "Between power and mithology: evidence of social inequality and hierarchisation in the Iberian megalithic”. En P. Díaz del Río y L. García (eds.): Social Inequality in Iberian Late Prehistory. British Archaeological Reports, International Series 1525. Archaeopress. Oxford: 37-52.

Bueno Ramírez, P.; Balbín Behrmann, R.y Barroso Bermejo, R. 2005: "Hiérarchisation et metallurgie: statues armées dans la Péninsule Ibérique". L'Anthropologie 109: 577-640.

Caamaño Gesto, J.M. 2007: "O Calcolítico e a Edad del Bronce". En X.R. Barreiro Fernández y R. Villares Paz (coord.): A Gran Historia de Galicia. Prehistoria de Galicia I, 2. La Voz de Galicia. A Coruña: 8-223.

Calo Lourido, F. y Sierra Rodríguez, X.C. 1983: "As orixenes do castrexo no Bronce Final". En G. Pereira (ed.): Estudios de Cultura Castrexa e de História Antiga de Galicia. Universidade de Santiago de Compostela. Santiago de Compostela: 19-85.

Canha, A.J. 2002: Canedotes, povoado do Bronze Final do Alto Paiva. Faculdade de Letras da Universidade do Porto. Porto.

Cardoso, J.L.; Senna-Martínez, J.C. y Valera, A. 1998: "Aspectos da economia alimentar do Bronce Pleno da Beira Alta: a fauna de grandes mamíferos das salas 2 e 20 do Buraco da Moura de S. Romão (Seia)". Trabalhos de Arqueologia do EAM. Revista Anual da Associação para o Estudo Arqueológico da Bacia do Mondego 3/4: 253-261.

Cardoso, M. 1936: "Novas urnas de largo bordo horizontal (um tipo regional de cerâmica primitiva)". Trabalhos de Antropologia e Etnologia 8 (1): 65-87.

Carvalho, P.M.S. 2005: "A necrópole megalítica da Senhora do Monte (Penedono - Viseu: um espaço sagrado pré-histórico na Beira Alta". Estudos Pré-Históricos 12. Viseu.
Carvalho, P.M.S. y Gomes L.F.C. 2000: "O dolmen da Fonte Coberta (Alijó, Vila Real)". Estudos Pré-Históricos 8: 19-47.

Carvalho, P.M.S. y Gomes L.F.C. 2002/2003: “A cista do povoado da Senhora de Lurdes (S. João da Pesqueira, Viseu)". Estudos Pré-Históricos 10/11: 225-231.

Coelho, J. 1925: A necrópole do Paranho. Topografia Popular. Viseu.

Comendador Rey, B. 1998: Los inicios de la metalurgia en el Noroeste de la Península Ibérica. Brigantium 11. Museo Arqueolóxico e Histórico Castelo de San Antón. Corunha.

Comendador Rey, B. 2001: "A Edad del Bronce en Galicia: balance e perspectives". En M. ${ }^{a}$ Eguileta, L. Orero y L. Ladro (eds.): Arqueologia Prehistórica na Tierra de Celanueva. Concello Celanova. Celanova: 103-130.

Cordeiro, I.; Silva, I y Fernandes, M.A. (coord.) 1995: A Idade do Bronze em Portugal. Discursos do Poder. Instituto Portugués de Museus. Lisboa.

Cunha, A.L. 1991: "Intervenção de emergência efectuada no Lugar de Fontela de Figueirido, Sardoura, Castelo de Paiva (Relatório de 1988/89)". Trabalhos de Antropologia e Etnologia 31: 199-219.

Cunha, A.L. 1995: "Anta da Arquinha da Moura (Tondela)". Trabalhos de Antropologia e Etnologia 35 (3): 133-151.

Criado, F.; Amado Reino, X.; Martínez López, M.C.; Cobas Fernández, I. y Parcero Oubiña, C. 2000: "Programa de corrección del impacto arqueológico de la gasificación de Galicia. Un ejemplo de gestión integral del património arqueológico". Complutum 11: 63-85.

Cruz, D.J. 1992: A mamoa 1 de Chã de Carvalhal (Serra da Aboboreira). Instituto de Arqueologia da Faculdade de Letras de Coimbra. Coimbra.

Cruz, D.J. 1997: "A necrópole do Bronze Final do "Paranho" (Molelos, Tondela, Viseu)". Estudos Pré-Históricos 5: 85-109.

Cruz, D.J. 1998: "Expressões funerárias e cultuais no Norte da Beira Alta (V. ${ }^{\circ}$ a II. ${ }^{\circ}$ milénios A.C.)". Estudos Pré-Históricos 6: 149-166.

Cruz, D.J. 1999: “A necrópole do Bronze Final do Paranho, Molelos, Tondela. Resultados das datações radiocarbónicas". Estudos Pré-Históricos 7: 263-270.

Cruz, D.J. 2001: O Alto Paiva: megalitismo, diversidade tumular e prácticas rituais durante a Pré-História Recente. Universidade de Coimbra. Coimbra.

Cruz, D.J.; Canha, A.J.; Loureiro, S.; Valinho, A. y Vieira, M.A. 2000: "Património arqueológico do concelho de Vila Nova de Paiva: a ocupação humana do Alto Paiva desde a Pré-História à Alta Idade Média”. Estudos Pré-Históricos 8: 251-264. 
Cruz, D.J.; Gomes, L.F.G. y Carvalho, P.M.S. 1998a: "Monumento 2 da Serra da Muna (Campo, Viseu): Resultados preliminares dos trabalhos de escavação". Actas do Colóquio A Pré-História na Beira Interior (Tondela, 1997). Estudos Pré-Históricos 6: 375-395.

Cruz, D.J.; Gomes, L.F.G. y Carvalho, P.M.S. 1998b: "O grupo de tumuli da Casinha Derribada (Concelho de Viseu)". Conimbriga 37: 5-76.

Cruz, D.J. y Gonçalves, A.H.B. 1995: "Mamoa 1 de Madorras (Sabrosa, Vila Real: Datações radiocarbónicas". Estudos Pré-Históricos 3: 151-159.

Cruz, D.J. y Gonçalves, A.H.B. 1998/1999: “A necrópole de Agra de Antas (S. Paio de Antas, Esposende, Braga”. Portugália 19-20: 5-27.

Cruz, D.J. y Vilaça, R. 1999: “O grupo de tumuli da Senhora da Ouvida (Castro Daire, Viseu)". Estudos Pré-Históricos 7: 129-161.

Chao Álvarez, F.J. y Álvarez Merayo, I.A. 2000: “A Madorra da Granxa: o túmulo máis grande de Galicia?". Brigantium 12: 41-63.

Delgado, J.F.N. 1887: "Reconhecimento scientifico dos jazigos de mármore e de alabastro de Santo Adrião e das grutas comprehendidas nos mesmos jazigos". Comunicações da Comissão dos Trabalhos Geológicos de Portugal 2: 44-55.

Delibes de Castro, G. y Rodríguez Colmenero, A. 1976: "Una nueva necrópolis de cistas en el noroeste peninsular". Letras de Deusto 6: 181-186.

Dinis, A. y Bettencourt, A.M.S. 2004: "Sondagens arqueológicas no Monte da Ola, Vila Fria, Viana do Castelo (Norte de Portugal”. Portugália 25: 71-85.

Eguileta, J.M.' 1999: A Baja Limia Galega na Prehistoria Recente. Arqueoloxía dunha Paisaxe na Galicia Interior. Depútación Provincial de Ourense. Ourense.

Fábregas, R. 1990/1991: "Industria lítica y mamoas del Noroeste: algunos caracteres fundamentales". Castrelos 3/4: 45-63.

Fábregas, R. 1993a: "Enterramientos tumulares en la Edad del Bronce? Nuevas evidencias para el Noroeste". Espacio, Tiempo y Forma. Revista de la Faculdad de Geografía e Historia, Prehistoria y Arqueología 6: 181-203.

Fábregas, R. 1993b: "El fenómeno tumular en el bronce del Noroeste". Actas del XXII Congresso Nacional de Arqueologia (Vigo, 1993) 1: 85-91. Vigo.

Fábregas, R. 1995: "La realidad funeraria en el Noroeste del Neolítico a la Edad del Bronce". En R. Fábregas, F. Pérez Losada y C. Fernández Ibañez (ed.): Arqueoloxía da Muerte na Península Ibérica desde as Orixes ata o Medievo. Universidad de Vigo. Xinzo de Limia: 95-125.

Fábregas, R. 2001: Los petroglifos y su contexto: un ejemplo de la Galicia meridional. Instituto de Estudios Vigueses. Vigo.
Fábregas, R.; Alonso Fernández, S.; Ameijenda Iglesias, A.; Grandal D’ Anglade, A.; Lazuén Fernández, T.; Lombera Hermida, A. de; Pérez Alberti, A.; Pérez Rama, M.; Rodríguez Álvarez, X.P.; Rodríguez Rellán, C.; Serna González, M.R.; Tierradillos Bernal, M. y Vaseao Rodríguez, M. 2009: "Nuevos resultados das intervencións arqueolóxicas no sur lucense. Os xacementos paleolíticos da depresión de Monforte (Monforte de Lemos), Cova Eirós (Triacastela) e Valdavara (Becerreá)". Gallaecia 28: 9-32.

Fábregas, R. y Bradley, R. 1995: "El silencio de las fuentes: prácticas funerarias en la Edad del Bronce del Noroeste y su contexto europeo". Complutum 6: 153-166.

Fábregas, R. y Meijide, G. 2000: "Prehistoria recente en Galicia. Evolución ou ruptura?". En V.O. Jorge (coord.): Actas do 3. ${ }^{\circ}$ Congresso de Arqueologia peninsular (Vila Real, 1999) 4, Pré-história recente da Península ibérica: 65-77. Porto.

Fábregas, R. y Penedo Romero, R. 1995: “Cistas decoradas y petroglifos: una revisión". Actas del XXII Congreso Nacional de Arqueologia (Vigo, 2003): 105-110. Vigo.

Fábregas, R. y Ruiz-Gálvez, M. 1994: “Ámbitos funerario y doméstico en la Prehistoria del NO. de la Península Ibérica”. Zephyrus 45: 143-159.

Fábregas, R y Ruiz-Gálvez, M. 1997: "El Noroeste de la Península Ibérica en el III. ${ }^{\circ}$ y II $^{\circ}$ milenios AC: propuestas para una síntesis". Sagvntvm 30: 191-216.

Fábregas, R. y Vilaseco Vázquez, X.I. 1998: “Prácticas funerarias no Bronce do Noroeste". En R. Fábregas (ed.): A Edad del Bronce en Galicia: nuevas perspectivas. Cadernos do Seminário de Sargadelos 77. Coruña: 191-219.

Fahlander, F. y Oestigaard, T. 2008: "The materiality of death: bodies, burials, beliefs". En F. Fahlander y T. Oestigaard (eds.): The materiality of death bodies, burials and beliefs. British Archaeological Reports, International Series 1768. Archaeopress. Oxford: 1-16.

Fortes, J. 1906: "A sepultura da Quinta da Água Branca (Edade do Cobre)". Portugália 2: 241-252.

Fortes, J. 1909: Gaya no passado. Mea villa de Gaya. Empresa Editorial do Guia Ilustrado de Portugal. Porto: 9-28.

Gomes, L.F.C. 1996: A necrópole megalítica da Lameira de Cima (Penedono-Viseu). Estudos Pré-Históricos 4. Viseu.

Gonçalves, A.H.B. y Cruz, D.J. 1994: "Resultados dos trabalhos de escavação da Mamoa 1 de Madorras (S. Lourenço de Riba Pinhão, Sabrosa, Vila Real)". Estudos Pré-históricos 2: 171-232.

Guimarães, C. 1983: "Notas bibliográficas para o estudo do povoamento pré-castrejo do concelho de Vila Nueva de Gaia". Arqueologia 8: 36-43. 
Harpsoe, C.H. y Ramos, M.F. 1985: "Lorga de Dine (Vinhais, Bragança)". Arqueologia 12: 202-204.

Harrison, R.J. 2004: Symbols and Warriors. Images of the European Bronze Age, Western Academic \& Specialist Press. Bristol.

Hill, J.D. 1993: "Can we recognise a different European past? A contrastive archaeology of later prehistoric settlements in southern England". Journal of European Archaeology 1: 57-75.

Hodder, I. 1990: The domestication of Europe. Structure and contingency in the Neolithic societies. Basil Blackwell. Oxford.

Jorge, S.O. 1980a: “A necrópole do Tapado da Caldeira-Baião". Arqueologia 2: 36-44.

Jorge, S.O. 1980b: “A estação arqueológica do Tapado da Caldeira, Baião”. Portugália nov. série 1: 29-50.

Jorge, S.O. 1983: "Duas datas de C14 para a sepultura 1 da estação do Tapado da Caldeira (Baião)". Arqueologia 8: 55-56.

Jorge, S.O. 1985: "Datas de Carbono 14 para a Pré-História Recente do Norte de Portugal: os dados e os problemas". Arqueologia 12: 154-183.

Jorge, S.O. 1988: O povoado da Bouça do Frade (Baião) no quadro do Bronce Final do Norte de Portugal. Monografias Arqueológicas do Grupo de Estudios Arqueológicos do Porto 2. Porto.

Jorge, S.O. 1991: "Idade do Bronze: apontamento sobre a natureza dos dados arqueológicos". Arqueologia 21: 12-15.

Jorge, S.O. 1999a: "Bronze Age stelai and menhirs of the Iberian Peninsula: discourses of power". En K. Demakopoulous, Ch. Eluere, J. Jensen, A. Jockennovel, J-P. Mohen (eds.): Gods and Heroes of the European Bronze Age. Thames \& Hudson. London: 114-122.

Jorge, S.O. 1999b: Domesticar a terra. As primeras comunidades agrárias em território português. Gradiva. Lisboa.

Jorge, S.O. 2006: O passado é redondo. Dialogando com os sentidos dos primeros recintos monumentais. Edições Afrontamento. Porto.

Jorge, S.O. y Jorge, V.O. 2006a: “Agricultores e pastores fixados no território. Do Neolítico Médio ao Bronze Médio". En C.A.B. Almeida (coord.): História do Douro e do Vinho do Porto. História Antiga da Região Duriense. Edições Afrontamento. Santa Maria da Feira: 106-163.

Jorge, S.O. y Jorge, V.O. 2006b: "Sociedades hierarquizadas, sociedades estratificadas? Bronze Final". En C.A.B. Almeida (coord.): História do Douro e do Vinho do Porto. História Antiga da Região Duriense. Edições Afrontamento. Santa Maria da Feira: $164-179$.

Jorge, V.O. 1980: "Escavação da Mamoa 1 de Outeiro de Gregos. Serra da Aboboreira, Baião". Portugália nov. série 1: 9-28.
Jorge, V.O. 1982: Megalitismo do Norte de Portugal: o distrito do Porto. Os monumentos e a sua problemática no contexto europeu. Universidade do Porto. Porto.

Jorge, V.O. 1983: "A escavação da Mamoa 2 de Cabritos". Arqueologia 8: 24-36.

Jorge, V.O. 1988: "Datas de Carbono 14 para a Mamoa de Chã de Parada 4". Arqueologia 17: 121-124.

Jorge, V.O. 1992: “As mamoas funerárias do Norte de Portugal (do Neolítico à Idade do Bronze Antigo) como elementos indicadores de uma progressiva complexidade social: esboço preliminar da questão". Revista de História da Faculdade de Letras-História, 2. ${ }^{a}$ série 9: 463-480.

Jorge, V.O. 1993: "Novas datas de C14 para estações pré-históricas do Norte de Portugal". Revista da Faculdade de Letras. História 2. ${ }^{\mathrm{a}}$ série 10: 417-432.

Jorge, V.O.; Alonso, F. y Delibrias, G. 1988: "Novas datas de Carbono 14 para mamoas da Serra da Aboboreira". Arqueologia 18: 95-98.

Jorge, V.O. y Jorge, S.O. 1990: "Statues-Menhirs et stèles du Nord du Portugal". Revista da Faculdade de Letras. História 2. ' série 8: 299-324.

Jorge, V.O. y Vilaça, R. 1985: "As mamoas de Cabritos (Serra da Aboboreira)". Arqueologia 11: 51-66.

Kalb, P. 1994: "Reflexões sobre a utilização de necrópoles megalíticas na Idade do Bronze". O Megalitismo no Centro de Portugal (Mangualde, Nov.1992). Estudos Pré-Históricos 2: 415-426.

Kalb, P. 1995: "O povoado de Nossa Senhora da Guia, Baiões". En Cordeiro, I. Silva y M.A. Fernandes (coord.): A Idade do Bronze em Portugal. Discursos de Poder. Instituto Portugués dos Museus. Lisboa: 68 .

Kalb, P. y Hock, M. 1979: "Escavações na necrópole de mamoas de Fonte da Malga-Viseu, Portugal". Beira Alta 38 (3): 595-604.

Ladra, L. 2003:" Nueva cista decorada na Galicia central?" Anuario Brigantino 26: 11 -23.

Leisner, V. 1958: "Notas sobre um vaso transmontano". Arqueologia e História 8, 3. ${ }^{a}$ série: 145-153.

Leisner, V. 1998: Die Megalithgraber der Iberischen Halbinsel. Der Westen. Madrider Forshungen I, Walter de Gruyter. Berlin.

Leisner, V. y Ribeiro, L. 1968:'Die dolmen von Carapito". Madrider Mitteilungen 9: 11-62.

Lobato, M. J. F. 1995: "A necrópole romana de Gulpilhares (Vila Nova de Gaia)". Portugália 16: 31-110.

López Cuevillas, F. 1930: "Nuevas cerámicas das antas galegas". Trabalhos da Sociedade Portuguesa de Antropologia e Etnologia 4: 263-282.

López Cuevillas, F. 1947: "Los vasos semiovoides y la cronología de los vasos de ancho borde horizontal". Boletin de la Comisión Provincial de Monu- 
mentos Históricos y Artísticos de Orense 16 (1): 1-12.

López Cuevillas, F. y Chamoso Lamas, M. 1958: “Una necrópolis de sepulturas planas". Cuadernos de Estudios Gallegos 13 (39): 273-283.

López Cuevillas, F. y Lorenzo Fernández, X. 1930: Vila de Calvos de Randin. Notas Etnográficas e Folklóricas. Seminario de Estudios Galegos. Santiago de Compostela.

López Sáez, J.A. y Cruz, D.J. 2002/2003: “Análisis polínicas da Orca das Castonairas (Vila Nova de Paiva, Viseu). Evolução ambiental durante a Pré-História Recente da região do Alto Paiva (Beira Alta)". Estudos Pré-Históricos 10/11: 55-86.

López Sáez, J.A., López García, P., Cruz, D.J. y Canha, A. 2000: "Paleovegetação e impacto humano durante a Pré-História Recente na região do Alto Paiva: palinologia do povoado do Bronze Final de Canedotes (Vila Nova de Paiva)". Estudos Pré-Históricos 8: 161-185.

Loureiro, S. 2003: O Castro de Vila Cova-à-Coelheira (Vila Nova de Paiva, Viseu): a ocupação proto-histórica. Faculdade de Letras da Universidade do Porto. Porto

Luengo y Martínez, J.M. 1965: "Las sepulturas de la Edad del Bronce descubiertas en Carnota”. La Voz de Galicia 21 de Maio: 13.

Maciñeira, F. 1941: "El vaso campaniforme y condiciones de sus intactos yacimientos tumulares en la estación de Puentes, del cabo Ortegal". Atlantis16: 356-369.

Martins, M.M. 1988: A Citânia de S. Julião, Vila Verde. Cadernos de Arqueologia-Monografias 2. Braga.

Martins, M.M. 1990: O povoamento proto-histórico e a romanização da bacia do curso Médio do Cávado. Cadernos de Arqueologia-Monografias 5. Braga.

Meijide, G. 1994: “El concepto de las relaciones atlánticas en la Edad del Bronce del noroeste". En L. Castro Pérez y S. Reboreda Morillo (coord.): Edad del Bronce. Actas del Curso de Verano de la Universidad de Vigo (Xinzo de Limia, 1993): 197 -231. Xinzo de Limia.

Meijide, G. 1995: “La necrópolis del Bronce Inicial del Agro de Nogueira (Toques, A Coruña)". Actas del XXII Congreso Nacional de Arqueologia (Vigo 2003) 2: 85-88. Vigo.

Meijide, G. 1996: "La necrópolis del Bronce inicial del Agro de Nogueira (Piñeiro, Toques, A Coruña) en el contexto funerario de su época". Homenaje a C. Alonso del Real. Universidade de Santiago de Compostela 1. Santiago de Compostela: 215-239.

Méndez Fernández, F. 1995: Informe valorativo de la excavación de urgencia de la cista de A Forxa (Vilariño das Touzas, Os Riós, Ourense). Dirección Xeral de Patrimonio Cultural da Xunta de Galicia, Santiago de Compostela.
Mercadal, O. 2001: "Estudio paleontológico de un resto óseo procedente de La Campa Torres (Gijón)". En J.L. Maya y F. Cuesta (eds.): El Castro de La Campa Torres. Periodo preromano. Serie Patrimonio 6, Ayuntamiento de Gijón. Gijón: 289-294.

Moita, I. 1966: "Características predominantes do grupo dolménico da Beira Alta”. Ethnos 5: 189-277.

Monteagudo, L.; García, A. y Lois, J. 1981: "El hacha de Salto (Rodeiro) y las primeras hachas de tope de dos asas en Europa". El Museu de Pontevedra 35: 117-162.

Obermaier, H. 1923: "Impresiones de un viaje prehistórico por Galicia”. Boletín de la Comisión de Monumentos Histórico Artísticos de Orense 7 (148149): 1-21, 25-47.

Parcero Oubiña, C. 1997: Documentación de un entorno castreño: trabajos arqueológicos en el área de Cameixa. Trabajos en Arqueología del Paisaje 1. Santiago de Compostela.

Peña Santos, A. 1985: "Las cistas de Gandón (Cangas de Morrazo, Pontevedra)". El Museu de Pontevedra 39: 78-99.

Peña Santos, A. 1992: Castro de Torroso (Mos, Pontevedra). Síntesis de las Memorias de las campañas de escavaciones 1984-1990. Arqueoloxía/Memorias 11. Xunta de Galicia. A Coruña.

Pereira, F.A. 1903: "Novas mamoas da Serra do Soajo". O Archeologo Portugués 8: 72-75.

Prieto-Martínez, P. 2007: "Volviendo a um mismo lugar: recipientes y espacios en un monumento megalítico gallego (NW de España)". Revista Portuguesa de Arqueologia 10 (2): 101-125.

Prieto Martínez, M.P.; Lantes Suárez, O. y Martínez Cortizas, A. 2009a: "Dos enterramientos de la Edad del Bronce en la Provincia de Ourense". Actas do 1. ${ }^{\circ}$ Congresso Transfronteiriço de Arqueologia (Montalegre, 2008). Revista Aqvae Flaviae 41: 93-105.

Prieto Martínez, M.P.; Martínez Cortizas, A.; Lantes Suárez, O. y Gil Agra, D. 2009b: "Estudio de la cerámica del yacimiento de fosas de Fraga do Zorro". Actas do 1. ${ }^{\circ}$ Congresso Transfronteiriço de Arqueologia (Montalegre, 2008). Revista Aqvae Flaviae 41: 107-121.

Prieto-Martínez, P.; Tabarés Domínguez, M. y Baqueiro Vidal, S. 2005: "Estudio da cultura material de A Devesa de Abaixo-Os Torradoiros". En F. Criado Boado y E. Cabrejas Domínguez (coord.): Obras públicas e patrimonio: estudios arqueolóxicos do corredor do Morrazo. TAPA. Traballos de Arqueoloxía e Património 35. Santiago de Compostela: 120-124.

Ramil Rego, P. 1993: "Evolución climática e historia de la vegetación durante el Pleistoceno Superior y el Holoceno en las regiones montañosas del Noroeste Ibérico". En A. Pérez Alberti, L. Guitian Rivera y P. Ramil-Rego (eds.): La Evolución del Pai- 
saje en las Montañas del Entorno de los Caminos Jacobeos. Ed. Xunta de Galicia. Santiago de Compostela: $25-60$.

Ramil Rego, P.; Dopazo Martínez, A. y Fernández Rodríguez, C. 1996a: "Cambios en las estrategias de explotación de los recursos vegetales en el Norte de la Península Ibérica”. Férvedes 3: 169-187.

Ramil Rego, P.; Taboada Castro, M.T.; Díaz-Fierros, F. y Aira Rodríguez, M.J. 1996b: "Modificación de la cubierta vegetal y acción antrópica en la región del Miño (Norte de Portugal) durante el Holoceno". En P. Ramil-Rego, C. Fernández Rodríguez y M. Rodríguez Guitián (coord.): Biogeografía Pleistocena - Holocena de la Península Ibérica. Xunta de Galicia. Santiago de Compostela: 199-214.

Ramil Soneira, J. y Vázquez Varela J.M. 1979: “Enterramiento en cista de la Edad del Bronce de ' $\mathrm{O} \mathrm{Cu}$ billon', Xermade (Lugo)". El Museu de Pontevedra 33: 61-68.

Rocha, A.S. 1: 1903 "As arcainhas do Seixo e da Sobredo". Portugália 1 (2): 12-22.

Rodríguez Casal, A. 1989: La necrópolis megalítica de Parxubeira. Monografias Urxentes do Museu 4, Museu Arqueolóxico Provincial. Coruña.

Rodríguez Gras, J.M. ${ }^{\text {a } 1974: ~ " U n ~ v a s o ~ y ~ u n ~ p u n ̃ a l ~ d e ~ l a ~}$ Edad del Bronce hallados en Malpica”. El Ideal Gallego 9 de xuño: 20-21.

Ruiz-Gálvez Priego, M. 1998: La Europa Atlántica en la Edad del Bronce. Un viaje a las raíces de la Europa occidental. Crítica/Arqueología. Barcelona.

Sampaio, H.A.; Bettencourt, A.M.S.; Barbosa, R.; Dinis, A. y Cruz, C.S. 2008: "A importância do povoado do Pego no Bronze Final do Noroeste de Portugal". En E. Ramil Rego (ed.): Actas do 1 Congreso Internacional de Arqueoloxía de Vilalba (Vilalba, 2008). Férvedes 5: 227-233.

Sanches, M.J. 1980: "Alguns vasos cerâmicos do Museu de Antropologia do Porto". Arqueologia 1: 12-18.

Sanches, M.J. 1992: Pré-História Recente no Planalto Mirandês (Leste de Trás-os-Montes). Ed. Grupo de Estudos de Arqueologia do Porto. Porto.

Sarmento, F. 1933: Dispersos. Universidade de Coimbra. Coimbra.

Santos, A.T. y Marques, J.N. 2007: "Os tumuli do Rochão (Castro Daire, Viseu)". Conímbriga 46: 27-51.

Senna-Martínez, J.C. 1989: Pré-História Recente da bacia do Médio e Alto Mondego. Algumas contribuições para um modelo sociocultural. Universidade Clássica de Lisboa. Lisboa.

Senna-Martínez, J.C. 1993: "A ocupación do Bronce Pleno da 'Sala 20' do Buraco da Moura de São Romão". Trabalhos de Arqueologia da EAM. Revista Anual da Associação para o Estudo Arqueológico da Bacia do Mondego. 1: 55-75.
Senna-Martínez, J.C. 2000a: “O Bronce Pleno. Uma transformação na continuidade?". Por Terras de Viriato. Arqueologia da Região de Viseu. Governo Civil do Distrito de Viseu e Museu Nacional de Arqueologia. Viseu: 105-114.

Senna-Martínez, J.C. 2000b: “O grupo Baiões/Santa Luzia no quadro do Bronze Final do Centro de Portugal". Por Terras de Viriato. Arqueologia da Região de Viseu. Governo Civil do Distrito de Viseu e Museu Nacional de Arqueologia. Viseu: 119 -131.

Senna-Martínez, J.C.; Ventura, J.M.Q. y Carvalho, H.A. 2007: “A Fraga dos Corvos (Macedo de Cavaleiros): um sítio de habitat da primeira Idade do Bronze em Trás-os-Montes Oriental. A Campanha 4 (2006)". Cadernos Terras Quentes 4: 85-110.

Senna-Martínez, J.C.; Ventura, J.M.Q.; Carvalho, H.A. y Figueiredo, E. 2006: "A Fraga dos Corvos (Macedo de Cavaleiros): um sítio de habitat da primeira Idade do Bronze em Trás-os-Montes Oriental. A Campanha 3 (2005)". Cadernos Terras Quentes 3: 61-85.

Silva, A. 2004: “As origens do povoamento. Megalitismo e tradição megalítica no concelho de Arouca: três mil anos de arquitectura funerária”. En A. Silva (coord.): Memórias da terra. Património arqueológico do concelho de Arouca. Câmara Municipal de Arouca. Arouca: 44-205.

Silva, A. y Leite, J. 2010: "The place of Cividade. An approach to Late Bronze Age/IronAge Transition in the Arouca valley (NW Portugal)". En A.M.S. Bettencourt, M.J. Sanches, L.B. Alves y R. Fábregas Valcarce (eds.): Conceptualizing space and place. On the role of agency, memory and identity in the construction of space from the Upper Paleolithic to the Iron Age in Europe. Proceedings of the 15th Congress of the International Union for Prehistoric and Protohistoric Sciences, Lisbon, September 2006, British Archaeological Reports, International Series 2058, Archaeopress, Oxford: 153-160.

Silva, A.C.F. 1985: "As fosas ovóides de Beiriz e a problemática das práticas funerárias no final da Idade do Bronze". Actas do Colóquio "Santos Graça” de Etnografia Marítima (Póvoa de Varzim, 1985). Póvoa de Varzim 3: 13-20.

Silva, A.C.F. 1993: "A Idade do Bronze em Portugal". En A.C.F. Silva, L. Raposo y C.T. Silva (eds.): Pré-História de Portugal. Universidade Aberta. Lisboa: 235-293.

Silva, A.C.F.; Lopes, A.B. y Maciel, T.P. 1981: “A necrópole do Bronze Inicial da Chã de Arefe (Durrães, Barcelos)". Arquivo do Alto Minho 26: 49-61.

Silva, E.J. 1995: "Megalitismo da bacia do Doro (margem sul)". Actas do $1 .^{\circ}$ Congresso de Arqueologia Peninsular (Porto, 1994), Trabalhos de Antropologia e Etnologia 35 (1): 35-46. 
Silva, E.J. y Marques, J.A.M. 1984: “Escavação de uma cista em Lordelo (Anha - Viana do Castelo)". Revista de História 1: 51-72.

Silva, E.J. y Marques, J.A.M. 1986: “Escavação arqueológica da Mamoa de Chafé - Viana do Castelo (Notícia preliminar)". Arqueologia 13: 207-208.

Silva, F.A.P. 1992: "Prospecção sistemática no planalto da Freita (Aveiro/Viseu) I. Monumentos megalíticos e de tradição megalítica - primeiros resultados". Trabalhos de Antropologia e Etnologia 32 (1/4): 235-254.

Silva, F.A.P. 1994: "Túmulos do Centro-Norte Litoral. Prolegómenos a uma periodização". Trabajos de Arqueologia da EAM. Revista Anual da Associação para o Estudo Arqueológico da Bacia do Mondego 2: 9-33.

Silva, F.A.P. 1997: “Contextos funerários da Idade do Bronze nos planaltos centrais do Centro-Norte Litoral português: tradição e inovação?”. En R. Balbín Behrmann y P. Bueno Ramírez (eds.): Actas del II Congreso de Arqueología Peninsular (Zamora, 1996) 2, Neolítico, Calcolítico y Bronce: 605-620. Zamora.

Silva, M.A. 1994: "A cista do Gorgolão (Vila da Ponte - Montalegre)". Portugália, nov. série 15: 137-146.

Soeiro, T. 1988: “A propósito de quatro necrópoles Proto-históricas do concelho de Esposende". Actas do Colóquia Manuel de Boaventura (Esposende 1985). Esposende 2: 35-62.

Sofaer, J.R. 2006: The body as material culture. Cambridge University Press. Cambridge.

Suárez Otero, J. 2002: "Die bronzezeit in Galicien". Madrider Mitteilungen 43: 1-21.

Taboada Chivite, J. 1971: "Noticias arqueológicas de la región del Támega (Verín)". Cuadernos de Estudios Galegos 26 (78): 45-63.

Valinho, A.T.S. 2003: A ocupação humana no Alto Paiva no I milénio a.C.: uma abordagem espacial. Faculdade de Letras da Universidade do Porto. Porto.

Vaquero Lastres, J. 1995a: "Túmulos del NW peninsular: escenas". Actas del XXII Congreso Nacional de Arqueologia (Vigo, 1993) 1: 39-45. Vigo.
Vaquero Lastres, J. 1995b:"Túmulos tardíos en el NW. RB1: estructuras". Actas del XXII Congreso Nacional de Arqueologia (Vigo, 1993) 1: 405-410. Vigo.

Vaquero Lastres, J. y Vázquez Collazo, S. 1995: “Túmulos tardíos en el NW. RB1: piezas". Actas del XXII Congreso Nacional de Arqueologia (Vigo, 1993) 1: 411-415. Vigo.

Vaseao Rodríguez, M.; Alonso Fernández, S.; Alonso Fernández, C.; Ameijenda Iglesias, A.; Blain, H.A.; Fábregas Valcarce, R.; Gala Gómez, M.; Lombera Hermida, A.; López-García, J.M.; Lorenzo Merino, C.; Lozano Ruiz, M.; Rodríguez Rellán, C.; Rosell i Ardèvol, J. y Serna González, M.R. 2009: "Nuevas fechas radiométricas para la Prehistoria del noroeste la Península Ibérica: la cueva Valdavara (Becerreá, Lugo)". Trabajos de Prehistoria 66 (1): 99-113.

Vázquez Liz, P. 2005: "Edad del Bronce: Devesa de Abaixo - Os Torradoiros". En F. Criado Boado y E. Cabrejas Domínguez (coord.): Obras públicas e patrimonio: estudios arqueolóxicos do corredor do Morrazo. TAPA. Traballos de Arqueoloxía e Património 35. Santiago de Compostela: 63-69.

Vázquez Varela, J.M. 1980a: "Enterramientos en cista de la Edad del Bronce en Galicia". Pontevedra 0: 23-40.

Vázquez Varela, J.M. 1980b: “Cistas decoradas en Galicia: una nueva manifestación artística de la Edad del Bronce". Brigantium 1: 41-48.

Viana, A. 1955: “A Cova da Moura, Carreço, Viana do Castelo". Actas do Congreso Nacional de Arqueologia (Zaragoza 1953): 481-497.

Villa, A. 2005: "Castros e recintos fortificados en el occidente de Asturias: estado de la cuestión". Boletín Auriense 33: 115-146.

Villa, A. y Cabo, L.C. 2003: "Depósito funerario y recinto fortificado de la Edad del Bronce en el castro del Chao Samartín: argumentos para su datación". Trabajos de Prehistoria 60 (2): 143-151.

Vilaça, R. y Cruz D.J. 1999: "Práticas funerárias e cultuais dos finais da Idade do Bronze na Beira Alta". Arqueologia 24: 73-99. 